\title{
Review on heterophase/homophase junctions for efficient photocatalysis: The case of phase transition construction
}

\author{
Kai Yang a,d, Xiaoxiao Li a, Changlin Yu a,b,*, Debin Zeng a, Fanyun Chen a, Kailian Zhang a, \\ Weiya Huang a, Hongbing $\mathrm{Ji}^{\mathrm{c}^{* *}}$ \\ a School of Metallurgy and Chemical Engineering, Jiangxi University of Science and Technology, Ganzhou 341000, Jiangxi, China \\ ${ }^{\mathrm{b}}$ Key Laboratory of Petrochemical Pollution Process and Control, Faculty of Environmental Science and Engineering, Maoming 525000, Guangdong, \\ China \\ c School of Chemical Engineering, Guangdong University of Petrochemical Technology, Maoming 525000, Guangdong, China
}

\section{A R T I C L E I N F O}

\section{Article history:}

Received 9 Novermber 2018

Accepted 26 December 2018

Published 5 June 2019

\section{Keywords:}

Phase transformation

Phase junction

Photocatalysis

Efficient charge transfer

\begin{abstract}
A B S T R A C T
Semiconductor photocatalysts are extensively applied in environmental treatment and energy conversion. However, one of their major disadvantages is their relatively low photocatalytic performance owing to the recombination of generated electron-hole pairs. The presence of the phase junction is an effective way to promote the photocatalytic activity by increasing the separation efficiency of the electron-hole pairs. Accordingly, extensive research has been conducted on the design of phase junctions of photocatalysts to improve their charge transfer properties and efficiencies. Therefore, for the design of an appropriate phase junction and the understanding of the mechanism of electron-hole separation, the development of the photocatalytic phase junction, including the preparation methods of the heterogeneous materials, is tremendously important and helpful. Herein, the commonly used, externally induced phase transformation fabrication techniques and the primary components of the semiconductors are reviewed. Future directions will still focus on the design and optimization of the phase junction of photocatalytic materials according to the phase transition with higher efficiencies for broadband responses and solar energy utilization. Additionally, the most popular phase transformation fabrication techniques of phase junctions are briefly reviewed from the application viewpoint.
\end{abstract}

(C) 2019, Dalian Institute of Chemical Physics, Chinese Academy of Sciences. Published by Elsevier B.V. All rights reserved.

\section{Introduction}

The efficient utilization of solar energy is a frontier research field in the 21st century with intense competition in various countries. Accordingly, photocatalysis is a very attractive approach used for the utilization of solar energy [1-4]. Given that photocatalytic materials are usually faced with various problems, including narrow spectral responses, low-quantum efficiency, poor stability, and recycling difficulties [2,5-7], considerable strides ought to be expended to achieve the

\footnotetext{
*Corresponding author. Tel/Fax:+86-797-8312334; E-mail: yuchanglinjx@163.com(C.Yu); jihb@mail.sysu.edu.cn (H. Ji) This work was supported by the National Natural Science Foundation of China (21707055, 21567008, 21607064), Program of Qingjiang Excellent Young Talents, Jiangxi University of Science and Technology, Program of 5511 Talents in Scientific and Technological Innovation of Jiangxi Province (20165BCB18014), Academic and Technical Leaders of the Main Disciplines in Jiangxi Province (20172BCB22018), Jiangxi Province Natural Science Foundation (20161BAB203090, 20181BAB213010, 20181BAB203018), Young Science Foundation of Jiangxi Province Education Office (GJJ160671), and Open Project Program of the State Key Laboratory of Photocatalysis on Energy and Environment (SKLPEE-KF201712) in Fuzhou University. DOI: S1872-2067(19)63290-0 | http://www.sciencedirect.com/science/journal/18722067 | Chin. J. Catal., Vol. 40, No. 6, June 2019
} 
desired environmental treatment and the production of clean and sustainable energy. The latter could be achieved by converting solar energy efficiently on a large scale and at a low cost utilizing multiple methodologies, including photocatalytic pollutant degradation [8-12], photocatalytic water splitting [13-18], and generation of valuable chemical fuels from photocatalytic $\mathrm{CO}_{2}$ reduction [19-21]. Therefore, the development of photocatalytic materials with wide spectral responses (corresponding solar spectrum), increased activity, and increased light stability plays key roles in improving the utilization efficiency of solar energy, and in the expansion of the use of photocatalysis.

At present, semiconductors that are used as photocatalysts mainly include metal oxides $\left(\mathrm{TiO}_{2}\right.$ [22] and $\mathrm{ZnO}$ [23]), noble metal compounds $\left(\mathrm{Ag}_{3} \mathrm{PO}_{4}[24]\right.$ and $\mathrm{AgCO}_{3}$ [25]), sulfides (CdS [26] and ZnS [27]), nonmetallic elementary substances (elemental phosphorus [28,29] and $\mathrm{S}_{8}$ [30]), and polymers ( $\mathrm{g}-\mathrm{C}_{3} \mathrm{~N}_{4}$ [31]). This particular area has become a hot-spot research area in recent years. Among these types of semiconductors, metal oxides generally have a wide bandgap and can only use the sun's ultraviolet light radiation, thus limiting their efficiency. Noble metal compounds are not suitable for large-scale applications because of their high cost. Sulfides or nonmetallic elements are prone to photo-corrosion and have poor stability. Additionally, the photo-generated electron and hole recombination rates of the polymers are high. The maximum energy conversion from solar energy is in the range of $1 \%-5 \%$ and does not meet the commercial requirement $(\geq 10 \%$ ) [32]. Development of highly active, stable, and inexpensive photocatalytic materials is a core task associated with the improvement of solar energy efficiency. Visible light absorption can be improved by doping or by surface modifications, but the photo-induced electron and hole recombination is still a serious issue in a single semiconductor. In addition, a single semiconductor cannot have a narrower bandgap, a negative conduction band, and a more positive valence band at the same time. Correspondingly, the heterophase/homophase junction is the most commonly used way to improve the photocatalytic performance in semiconductors. It improves the photocatalytic activity in two ways: one is to widen the photoresponse range of the semiconductor materials, and the other is to improve the efficiency of the separated photogenerated electrons from holes.

\section{Advantages and challenges of heterophase/homophase junction in photocatalysts}

The construction of the phase junction is one of the methods used to effectively improve the photocatalytic activity and ameliorate the aforementioned problems associated with these materials. These materials can be classified (a) into three types (I, II, and III) [33] according to the relative position of the two semiconductor bands, and (b) into the p-n type and $\mathrm{Z}$ scheme [34-36] according to the different electron transfer pathways, as shown in Fig. 1. When different semiconductors, such as the p-type (holes being the majority charge carriers) or n-type (electrons being the majority charge carriers), come into close contact, a junction will be formed, and a potential difference will be established on both sides of the junction owing to the differences in their respective energy bands and other properties. The existence of the space potential difference can make the photo-generating carrier inject charged particles from one semiconductor energy level to another semiconductor energy level, thus facilitating the separation of electrons and holes, and improving the efficiency of photocatalysis [4,37]. Considering the p-n junction as an example, when the two types of carriers coexist in the two regions, a thin p-n junction is formed at their boundary layer. Owing to the high concentration of holes in the p-type region and electrons in the n-type region, diffusion drives the motion of electrons and holes toward the junction. A spatially charged

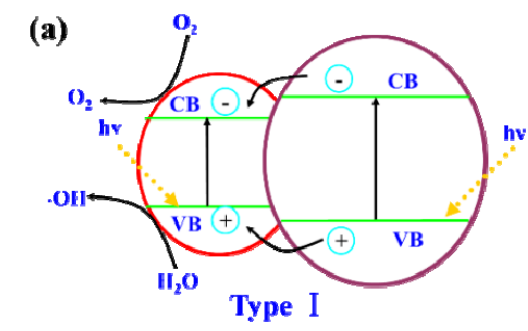

Type I

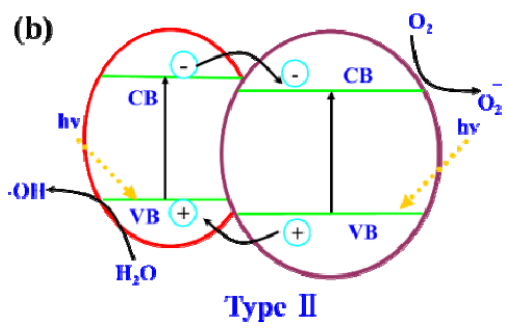

Type II (c)

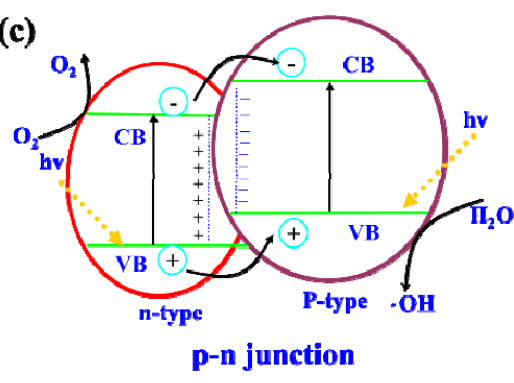

(d)

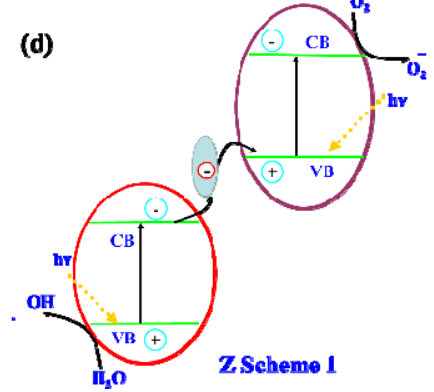

(e)

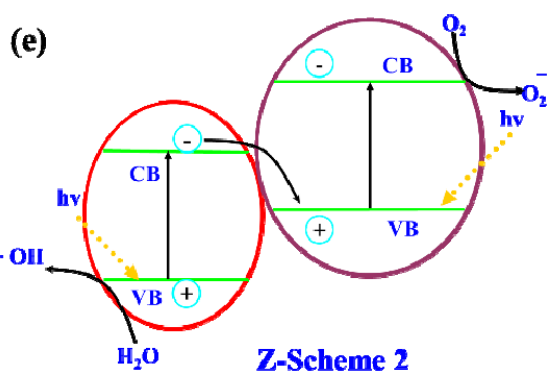

Fig. 1. Schematic representation of five types of heterojunction systems. 
region is formed near the boundary of the p-n junction. The $\mathrm{p}$-type region has a negative charge, while the n-type region has a positive charge, thereby forming a strong local electric field across the junction. Subject to the local electric field of the junction, charge accumulates at both ends of the junction to form a potential difference, which can then be used as a driving force to effectively separate the photo-induced charges [38-40].

In most cases, the construction of the phase junction requires special preparation technology and a good lattice mismatch [41-45]. Additionally, the nanosized semiconductor requirements for lattice matching are not stringent, and the nano-heterojunction interface, in conjunction with more reliable material selections and preparation methods, is extensively used. Nano-heterojunction materials have the advantage of the small sizes and particle confined effects combined with the characteristics of fast moving carriers, which can lead to unique properties that single-component nanomaterials or body phase heterojunctions do not have [46-48]. Nanocrystalline heterostructures are generally designed and used. For example, semiconductor nanocarbon and nanometal heterostructures can facilitate the rapid transfer of photogenerated electrons [49]. Therefore, considerable efforts have been expended in recent years on the design and fabrication of nanophase junctions for improving the photocatalytic activity. Although the heterojunction has an excellent performance, it is not composed of a single element, and its construction is based on a step-by-step reaction process. First, it is necessary to synthesize the two components of the heterojunction separately. The heterojunction is formed subsequently by using a second binding process. The reaction is complex, time consuming, and not environmentally friendly. Compared to the heterojunction, the homogenous junction is constructed with the same material, and based on the established phase transition, it can also achieve a highly efficient separation of photogenerated carriers. Homogenization does not require the introduction of other elements and has, thus, attracted considerable attention [50-52]. However, the formation of the homojunction is very difficult. Most of the homojunction structures are formed by semiconductors with different crystal phases in the phase transition process, such as anatase/rutile $\mathrm{TiO}_{2}, \alpha / \beta$ phase $\mathrm{Ga}_{2} \mathrm{O}_{3}$, or hexagonal/cubic CdS. Because of the similar chemical compositions, the band structures of these semiconductor materials cannot be easily modified. Therefore, only a few studies exist in the literature on the homojunction of homocrystalline materials.

Despite the existence of several review papers on phase junctions, such as semiconductor/semiconductor junctions, semiconductor/metal junctions, semiconductor/nonmetal junctions, and surface heterojunctions [4,14-15,47,53-59], an extensive review of the rational designs of phase junctions using fabrication methods, based on externally induced phase transitions, is still necessary to provide readers with an understanding of the current developments in this dynamic research field. In this study, the current research status is discussed in relation to the progress of low-cost applications with the efficient use of constructed nanophase junctions in photocatalysis.

\section{Fabrication strategies of heterophase/homophase junction photocatalysts}

As mentioned above, the creation of heterophase/homophase structures on the photocatalysts plays important roles in their photocatalytic activities [60,61]. From the viewpoint of the structural origin, the heterojunctions/homojunctions can be categorized into the composite phase (consisted of two or three different phases), the in-situ growth composite phase, and the phase-, facet- and van der Waals type junctions of a single substance. The junctions of a single substance can be constructed from different crystalline phases of the same chemical composition, like anatase/rutile $\mathrm{TiO}_{2}$ [62], $\alpha / \beta-\mathrm{Bi}_{2} \mathrm{O}_{3}$ [63], and the $\alpha / \gamma-\mathrm{Bi}_{2} \mathrm{O}_{3}$ homojunction [64], whereby different crystal facets of the single same semiconductor $[65,66]$ are stacked on a layer-by-layer basis on two-dimensional materials $[67,68]$.

\subsection{Heterophase junctions of two or three different phases}

Based on the recombination processes in different semiconductors that aim to the formation of heterophase junction structures, the optical absorption threshold can be effectively expanded, and the separation efficiency of the photogenerated carriers can be improved. Semiconductor recombination can transfer photogenerated electrons from the conduction band with a higher conductance to the band with a lower conductance so that the electrons and holes cannot be recombined, thus improving the photocatalytic activity of the photocatalyst. Numerous techniques have been developed to establish nanostructured heterophase junctions as well as the heterogeneous photoelectrodes using facile, low-cost, and energy-efficient methods, such as hydrothermal/solvothermal methods, electrochemical deposition, chemical bath deposition, sol-gel processes, and chemical precipitation [69-101]. Previously, we reviewed some typical heterophase junctions [9], such as $\mathrm{TiO}_{2}$-based, Ag-based [100], ZnO-based, and metal-sulfide-based heterophase junctions. Additionally, many heterojunction semiconductors have been studied by combining two semiconductor types, as shown in Table 1. For example, in the $\mathrm{CdS}-\mathrm{TiO}_{2}$ composite photocatalyst $[103,104]$, the composite CdS is excited by visible light to produce photogenerated electrons and holes. Because the lower energy level of the conduction band of $\mathrm{CdS}$ is higher than that of $\mathrm{TiO}_{2}$, the photogenerated electrons will be transmitted to the conduction band of $\mathrm{TiO}_{2}$ through the two-phase interface, and the photogenerated holes will be left on the CdS, thus realizing the spatial separation of the positions of the photogenerated charges. Two of the most important issues in the system are lattice matching and contact tightness. Chen et al. [104] found that the $\mathrm{CdS}-\mathrm{TiO}_{2}$ obtained using a single-step method can result in a better interfacial contact performance than the two-step method. Thus, higher photocatalytic activity was obtained. Inserting narrow bandgap semiconductors between layers of inorganic layered 
Table 1

Typical nano-heterophase junctions of photocatalysts.

\begin{tabular}{|c|c|c|c|}
\hline $\begin{array}{l}\text { Nano-hetero- } \\
\text { phase junctions }\end{array}$ & Production of $\mathrm{H}_{2}$ from water splitting & Generation of $\mathrm{C}_{x} \mathrm{H}_{y} \mathrm{O}_{z}$ from $\mathrm{CO}_{2}$ reduction & $\begin{array}{c}\text { Photocatalytic degradation } \\
\text { of pollutions }\end{array}$ \\
\hline p-n type & $\mathrm{Cu}_{2} \mathrm{~S} / \mathrm{CdS}[69], \mathrm{MoS}_{2} / \mathrm{CdS}$ [70], $\mathrm{CuO} / \mathrm{ZnO}[71]$ & $\mathrm{CuO} / \mathrm{TiO}_{2-x} \mathrm{~N}[84], \mathrm{CuInS}_{2} / \mathrm{TiO}_{2}[85]$ & $\begin{array}{c}\mathrm{Ag}_{2} \mathrm{O} \text { and } \mathrm{NaTaO}_{3}[92], \mathrm{CuInSe}_{2} / \mathrm{ZnO} \\
\text { [93], BiOI/ZnO [94] }\end{array}$ \\
\hline Z scheme & $\begin{array}{c}\mathrm{WO}_{3} / \mathrm{g}-\mathrm{C}_{3} \mathrm{~N}_{4}[72], \mathrm{ZnO} / \mathrm{Cd} / \mathrm{CdS}[73] \\
\mathrm{g}-\mathrm{C}_{3} \mathrm{~N}_{4} / \mathrm{Au} / \mathrm{CdS} \text { [74], } \mathrm{CdS} / \mathrm{SiC}[75]\end{array}$ & $\begin{array}{c}\mathrm{Ag}_{3} \mathrm{PO}_{4} / \mathrm{Ag} / \mathrm{g}-\mathrm{C}_{3} \mathrm{~N}_{4} \text { [86], } \mathrm{Fe}_{2} \mathrm{~V}_{4} \mathrm{O}_{13} / \mathrm{RGO} / \mathrm{CdS} \text { [87] } \\
\mathrm{TaON} / \mathrm{Ag} / \mathrm{Ru} \mathrm{BLRu}^{\prime}[88]\end{array}$ & $\mathrm{Ag}_{2} \mathrm{CrO}_{4} / \mathrm{GO}[95], \mathrm{C}_{3} \mathrm{~N}_{4} / \mathrm{TiO}_{2}[96]$ \\
\hline Type I & $\begin{array}{c}\mathrm{TiO}_{2} / \mathrm{CuO} \text { [76], CdSe/CdS [77], } \mathrm{MoS}_{2} / \mathrm{g}-\mathrm{C}_{3} \mathrm{~N}_{4} \\
\text { [78], CdS/ZnS [79] }\end{array}$ & $\mathrm{Bi}_{2} \mathrm{~S}_{3} / \mathrm{CdS}[89]$ & $\mathrm{Sb}_{2} \mathrm{~S}_{3} / \mathrm{TiO}_{2}$ [97], $\mathrm{TiO}_{2} / \mathrm{CuO}[98]$ \\
\hline Type II & $\begin{array}{c}\mathrm{g}-\mathrm{C}_{3} \mathrm{~N}_{4} / \mathrm{g}-\mathrm{C}_{3} \mathrm{~N}_{4}[80], \mathrm{g}-\mathrm{C}_{3} \mathrm{~N}_{4} / \text { polypyrrole [81], } \\
\mathrm{g}-\mathrm{C}_{3} \mathrm{~N}_{4} / \mathrm{SrTiO}_{3}[82], \mathrm{CdS} / \mathrm{g}-\mathrm{C}_{3} \mathrm{~N}_{4}[83]\end{array}$ & $\mathrm{ZnO} / \mathrm{g}-\mathrm{C}_{3} \mathrm{~N}_{4}[90], \mathrm{Cu}_{2} \mathrm{O} / \mathrm{TiO}_{2}[91]$ & $\begin{array}{c}\mathrm{Bi}_{2} \mathrm{WO}_{6} / \mathrm{WO}_{3}[99], \mathrm{BiOI}^{-\mathrm{SnS}_{2}}[100], \\
\mathrm{BiOI} / \mathrm{ZnTiO}_{3}[101]\end{array}$ \\
\hline
\end{tabular}

materials, such as $\mathrm{CdS}$ into $\mathrm{H}_{4} \mathrm{Nb}_{6} \mathrm{O}_{17}, \mathrm{H}_{2} \mathrm{Ti}_{4} \mathrm{O}_{9}$, KTiNbO5, or microporous/mesoporous materials, can also realize the close contact of the catalyst interface and the directional transfer of charge, thus improving the effect of the photocatalytic charge separation.

\subsection{In situ growth of phase junction}

The properties of the phase junction interface determine the resistance of electron transfer. The ohmic contact can change the path of the electron transfer by optimizing the preparation or treatment conditions. Compared to this particular phase junction, the conductor transfer electron method is more powerful and can form a more reliable ohmic contact. In situ growth of phase junctions of semiconductor heterophase/homophase structures can be controlled by the microstructural or surface morphologies, as shown in Fig. 2. The motion patterns of the electrons and holes generated by photoexcitation are dependent on the crystallization and surface state of the materials [105-108]. For a single semiconductor, the microstructure or surface morphologies of the crystal can be controlled effectively, and the photoelectron and hole pairs can be separated along the internal or surface directions, thereby allowing the quantification of the photocatalytic activity.

In fact, for a semiconductor material, there are usually different crystal forms, and the transition requires time if the re-

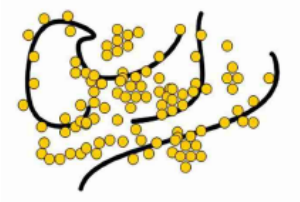

a

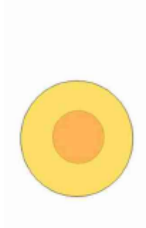

C

d

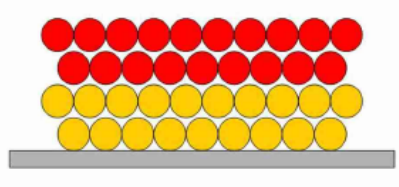

b

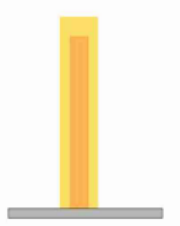

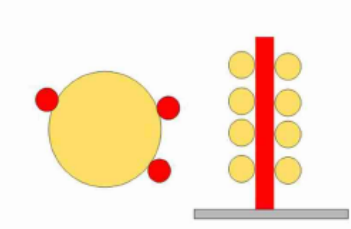

e
Fig. 2. Nanoscale heterogeneity. (a) Mixed type, (b) Laminated type, (c) Core-shell type, (d) Coaxial type, (e) Surface dispersion type. Reprinted with permission from Ref. [110]. Copyright 2009 China National Knowledge Internet. action needs to be controlled at the time at which the phase transition occurs. A semiconductor material with a mixed phase can be obtained. It is worth noting that the band-edge positions of different crystal phases of uniform materials usually change slightly because of the changes of the crystal lattice parameters. Therefore, "in situ junctions" can be produced by controlling the formation of different crystalline phases in the same substance. The most successful example of this theory is the formation of a surface heterogeneous junction between $\mathrm{TiO}_{2}$ anatase and rutile [57], which is further demonstrated by the $\alpha / \beta \mathrm{Ga}_{2} \mathrm{O}_{3}$ surface junction [109].

The formation of "in situ junctions" can be achieved by controlling the surface morphology of the semiconductor. The ability of the surface to regulate the electrons and holes will change owing to the arrangement of atoms, the state of the surface bonding, and the coordination condition. In other words, the density of electron states on different surfaces is not the same. Therefore, the generated electric potentials on adjacent crystal planes (surfaces) that drive the electrons and holes in the direction of the junction also vary. Accordingly, this can also achieve an effective spatial charge separation.

The methods described above mainly aim at the enhancement of the ability of photocharged migration on the surface of the catalyst. The actual acceleration point of the catalytic reaction should be the acceleration of the surface chemical reaction. Therefore, almost all of the above "in situ junctions" can be formed by combining homogenous and other (different) phases, or different homogenous surfaces. To improve the catalytic efficiency, it is necessary to accelerate the rate of the interfacial chemical reaction. As mentioned earlier, the reaction rate has increased to a new value by the introduction of sacrificial agents in the solution (loading Pt nanoparticles by the addition of chloroplatinic acid for hydrogen production). Correspondingly, it is necessary to introduce the co-catalyst by constructing the "in situ Schottky junction" [111,112]. Precious metal nanoparticles have a lower superpotential. Accordingly, the overpotential required for hydrogen production can be reduced. Owing to the existence of the Schottky barrier, a single electron is transferred from the semiconductor to the metal nanoparticle, but cannot be recombined with photogenerated holes. The metal nanoparticles can act as the capture center of the electron, and the photogenerated charge is thus spatially separated [112]. 


\subsection{In situ phase transformation (close interface)}

The regulation and control of the crystal type includes two aspects: one of them is the achievement of the mixed crystal for the enhanced charge separation, and the other is the identification of the temperature-dependence law or the externally induced synthesis of the phase transition. Numerous facile, low-cost, and energy efficient techniques of phase transformations, such as ion doping [113,114], oxide regulations $[115,116]$, wet chemical or solution-phase methods [117-120], pressure-induced phase transitions [121,122], calcination-induced phase transitions [123-125], self-induced self-surface phase junctions [126,127], pulse laser irradiation or UV/ozone-assistants [128,129], mechanical alloying [130], molten salt auxiliary [131], and electrochemistry methods $[132,133]$, have been extensively developed to fabricate heterojunctions/homojunctions. A large number of experimental studies have defined some of these laws that possess increased significance for the rational design of the crystal structure, the guidance of the synthesis, and the optimization of the catalytic performance of the catalyst [134].

\subsubsection{Anionic and cationic regulations}

Introducing a small number of anions into the semiconductor photocatalyst will influence the phase transition of undoped semiconductors. For example, the introduction of small, low-valence anions (such as $\mathrm{Cl}^{-}, \mathrm{F}^{-}$) can promote the formation of the rutile phase in $\mathrm{TiO}_{2}$. However, the introduction of high-valence anions (such as $\mathrm{PO}_{4}{ }^{3-}$ and $\mathrm{SO}_{4}{ }^{2-}$ ) with large radii is not conducive to the transformation of anatase to rutile $[135,136]$. The percentage of anatase in the surface region can increase from $2 \%$ to $75 \%$ with the increase of the content of $\mathrm{SO}_{4}{ }^{2-}$ in $\mathrm{TiO}_{2}$ from 0 to $3 \mathrm{wt} \%$. In other words, smaller anionic valency makes the formation of rutile titanium dioxide more favorable. This also explains why the sulfuric acid process cannot easily generate rutile products, while the chlorination process can be easily executed in an industrial setting. In effect, when the doped ion radius is greater than or less than the $\mathrm{Ti}^{4+}$ radius, the doped ion enters the $\mathrm{TiO}_{2}$ matrix and generates lattice defects that improve the lattice energy. This energy should be released before the phase transition, which makes the anatase $\mathrm{TiO}_{2}$ more stable. Accordingly, this leads to the increase of the anatase-rutile phase transition temperature. However, it is worth noting that different phase structures of $\mathrm{TiO}_{2}-\mathrm{SO}_{4}{ }^{2-}$ samples can be obtained by this method at the same increased temperature (Fig. 3), thus resulting in activities that are six times higher than those of $\mathrm{P} 25$ in the photocatalytic $\mathrm{H}_{2}$ production of the reformation of methanol. In the chart on the right part of Fig. 3, small anatase particles were well dispersed on the large rutile particles to construct an intimate anatase-rutile phase junction, which is conducive to the efficient charge transfer.

The anions $\mathrm{NO}_{3}{ }^{-}, \mathrm{HCO}_{3}{ }^{-}, \mathrm{PO}_{4}{ }^{3-}, \mathrm{SiO}_{3}{ }^{2-}$, and $\mathrm{MoO}_{4}{ }^{2-}$ can be utilized to regulate the anatase-rutile phase of $\mathrm{TiO}_{2}$ [137]. Larger anions are more favorable to the formation of anatase-type titanium dioxide. Experiments by Devi et al. [138] confirmed that only anatase exists at $700{ }^{\circ} \mathrm{C}$ for $\mathrm{TiO}_{2}$ doped $\mathrm{Mo}^{6+}$, and the rutile phase appears at $700{ }^{\circ} \mathrm{C}$ for doped $\mathrm{Mn}^{2+}$. This may be owing to the fact that the doping of high-valence ions $\left(\mathrm{Mo}^{6+}\right)$ makes the Fermi energy level drift upward, raises the surface barrier, narrows the charge region, and ensures an effective separation of the photogenerated electrons and holes
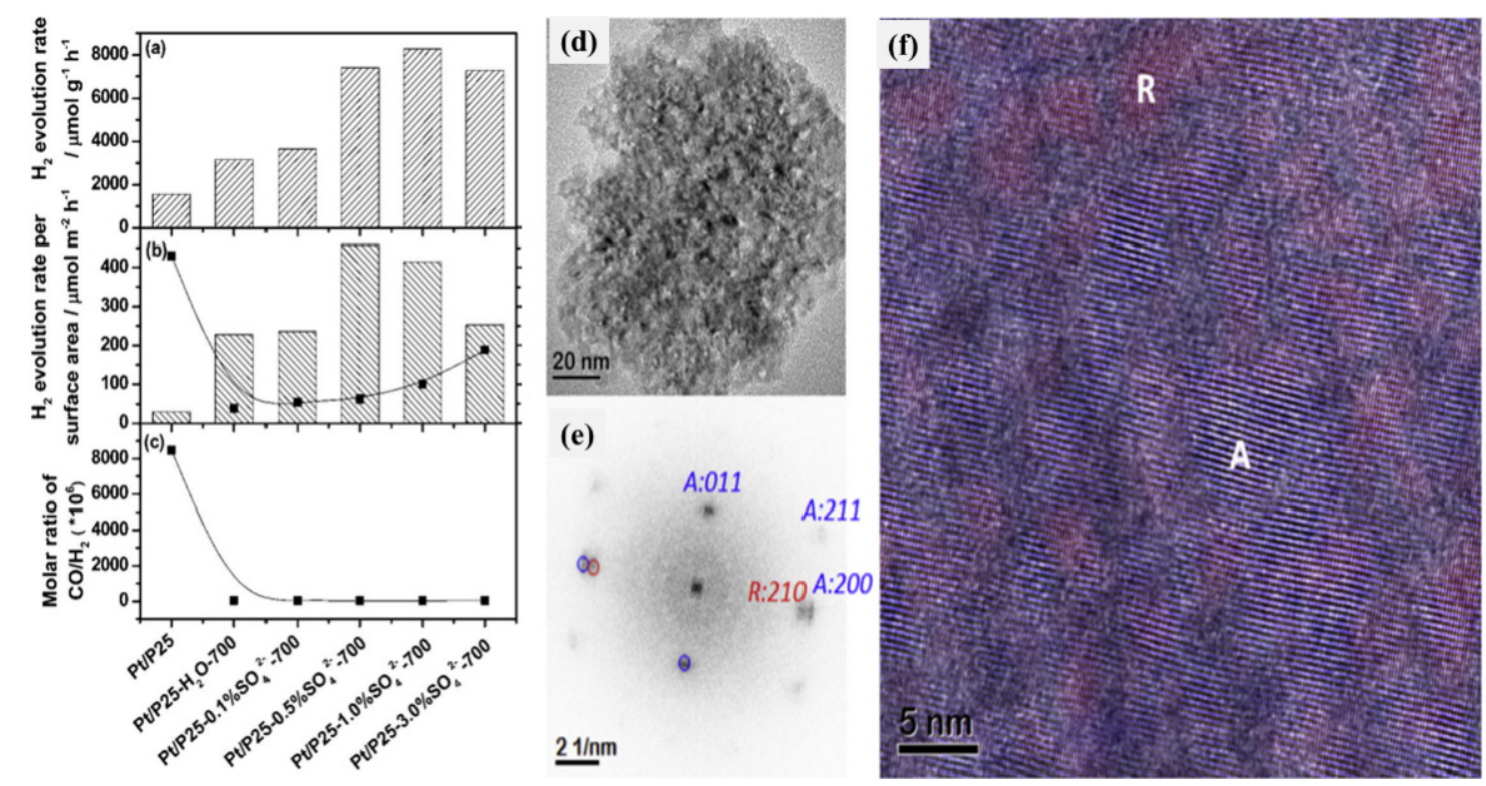

Fig. 3. (a) Overall photocatalytic activity of $\mathrm{H}_{2}$ production and (b) surface-specific photocatalytic activity of $\mathrm{H}_{2} \mathrm{production}$ of $\mathrm{Pt} / \mathrm{P} 25$, $\mathrm{Pt} / \mathrm{P} 25-\mathrm{H}_{2} \mathrm{O}-700$, and $\mathrm{Pt} / \mathrm{P} 25-\mathrm{x} \% \mathrm{SO}_{4}{ }^{2-}-700$. The solid line in (b) indicates the surface area of the samples. (c) CO selectivities of Pt/P25, Pt/P25- $\mathrm{H}_{2} \mathrm{O}-700$, and $\mathrm{Pt} / \mathrm{P} 25-\mathrm{x} \% \mathrm{SO}_{4}{ }^{2-}-700$ catalysts. (d) TEM image of typical agglomerates of nanoparticles, (e) fast Fourier transform of the HRTEM image, (f) HRTEM image and colorization of anatase (A, blue) and rutile (R, red) by reverse FFT based on the respective anatase and rutile spots observed in (e) (for interpretation of the references to different colors in this figure, the reader is referred to the web version of this article). Reprinted with permission from Refs. [136] and [119]. Copyright 2012 Royal Society of Chemistry, Copyright 2014 Elsevier. 
in the presence of a strong electric field, thus enhancing the photodegradation effect. Liu et al. [119] found that N3- doping can promote the formation of the rutile phase to form heterojunctions, reduce the bandgap of the $\mathrm{TiO}_{2}$ semiconductor, and expand the irradiation light from ultraviolet to visible light. Tian et al. [139] has studied the effect of $\mathrm{S}^{2-}$ doping on the ratio of anatase to rutile. The results show that the higher the $\mathrm{S}^{2-}$ doping is, the higher the ratio of anatase to rutile is, which is more favorable to the photocatalytic activity. Pichavant et al. [140] obtained the interfaced anatase-rutile photocatalysts by thermohydrolysis using very low levels (less than $0.5 \%$ ) of Sn(IV) that acted as a rutile phase promoter, as shown in Fig. 3. This process is much more direct than the coprecipitation of the amorphous product and is followed by the hydrothermal treatment process.

The Sn(IV) content can accurately control the anatase-rutile ratio and the nanoparticles obtained (diameters of $10 \mathrm{~nm}$ ) exhibit epitaxial relationships between the anatase (200) and rutile (210) planes, thus building porous submicronic composite agglomerates with increased specific surface area (200 $\mathrm{m}^{2} / \mathrm{g}$ ). Su et al. [141] modified the $\mathrm{Bi}$ atoms on the $\mathrm{BiVO}_{4}$ surface by $\mathrm{ZnO}$ coating and etching treatments. Based on this coating process, the $\mathrm{Zn}$ doping on the surface lowered the Fermi level of $\mathrm{BiVO}_{4}$ and a $\mathrm{BiVO}_{4} / \mathrm{Zn}: \mathrm{BiVO}_{4}$ homojunction with a type II band alignment was formed. The construction of the $\mathrm{BiVO}_{4}$ homojunction improved the charge transfer process and avoided the surface electron trapping, thereby exhibiting an enhanced PEC performance. Therefore, anionic and cationic doping can effectively regulate the phase transition and improve the photocatalytic activity of semiconductor photocatalysts.

\subsubsection{Oxide regulations}

Introducing oxide in the photocatalyst can also regulate its phase transition and influence the photocatalytic activity. Jung et al. [142] showed that the addition of $\mathrm{Al}_{2} \mathrm{O}_{3}$ into $\mathrm{TiO}_{2}$ for the thorough transformation of anatase-rutile types has an obvious inhibitory effect, the calcining temperature is as high as $800{ }^{\circ} \mathrm{C}$, and anatase $\mathrm{TiO}_{2}$ is still the main crystal structure with a specific spatial extent regarding the rutile phase. Li et al. [143] found that the addition of $\mathrm{Nd}_{2} \mathrm{O}_{3}$ has an effect on the surface phase of $\mathrm{TiO}_{2}$ and on the photocatalytic activity studied by UV Raman spectroscopy. They showed that the amount of $\mathrm{Nd}_{2} \mathrm{O}_{3}$ that was well dispersed onto the surface of $\mathrm{Nd}^{-\mathrm{TiO}_{2}}$ particles had a higher surface area and a wider optical response, and could tune the crystalline phase and composition of $\mathrm{Nd}^{-\mathrm{TiO}_{2}}$ calcined by high temperatures, inhibit the crystal size agglomeration, and transform the anatase phase to the rutile phase. Additionally, $\mathrm{Nd}-\mathrm{TiO}_{2}$ nanoparticles are more reactive in the photocatalytic degradation of RhB. Nonmetal oxide, such as $\mathrm{SiO}_{2}$, can also regulate and effectively control the crystal type and the grain growth of $\mathrm{TiO}_{2}$ and improve the catalytic performance. $\mathrm{SiO}_{2}$ composite particles can effectively improve the lifetime of $\mathrm{TiO}_{2}$ catalysts, and the $\mathrm{TiO}_{2}-\mathrm{SiO}_{2}$ composite has a larger specific surface area and is more acidic than $\mathrm{TiO}_{2}$. The superior photocatalytic performance may be attributed to the bridging oxygen structures of $\mathrm{Ti}-\mathrm{O}-\mathrm{Si}$ from $\mathrm{TiO}_{2}$ and $\mathrm{SiO}_{2}$. This led to increased specific surface area and surface defects, which is advantageous to the photogenerated electron-hole separation, and promoted the photocatalytic reaction [144,145]. Furthermore, Ti-O-Si effectively inhibited the thorough phase transition of anatase to rutile, increased the stability of anatase, and prevented the accumulation of the $\mathrm{TiO}_{2}$ grain growth [146]. Periyat et al. [115] studied different silicon contents on the effect of the stability of the $\mathrm{TiO}_{2}$ anatase type. When the mass fraction of $\mathrm{SiO}_{2}$ was $15 \%$, rutile appeared and was maintained up to a calcined temperature of $1000^{\circ} \mathrm{C}$.

\subsubsection{Soft-chemical-route-induced phase junctions}

Soft chemical route uses the circuitous steps to prepare the nanomaterials based on a slow reaction process in the presence of mild reaction conditions. Common soft chemical methods include the sol-gel, hydrothermal, microemulsion, low-temperature solution phase, vapor deposition, precursor, microwave-assisted synthesis methods, and others. Sun et al. [58] successfully prepared $\alpha-/ \gamma-\mathrm{Bi}_{2} \mathrm{O}_{3}$ homojunctions via a hydrothermal method that exhibited a synergetic effect on the photocatalytic activity. The diffuse reflectance and impedance spectra determined the homojunction between the $\alpha-\mathrm{Bi}_{2} \mathrm{O}_{3}$ and $\gamma-\mathrm{Bi}_{2} \mathrm{O}_{3}$. Based on these, they pointed out the mechanism of the charge transfer and the separation on the interface of $\alpha-/ \gamma-\mathrm{Bi}_{2} \mathrm{O}_{3}$. Bera et al. [147] and Shi et al. [59] also successfully
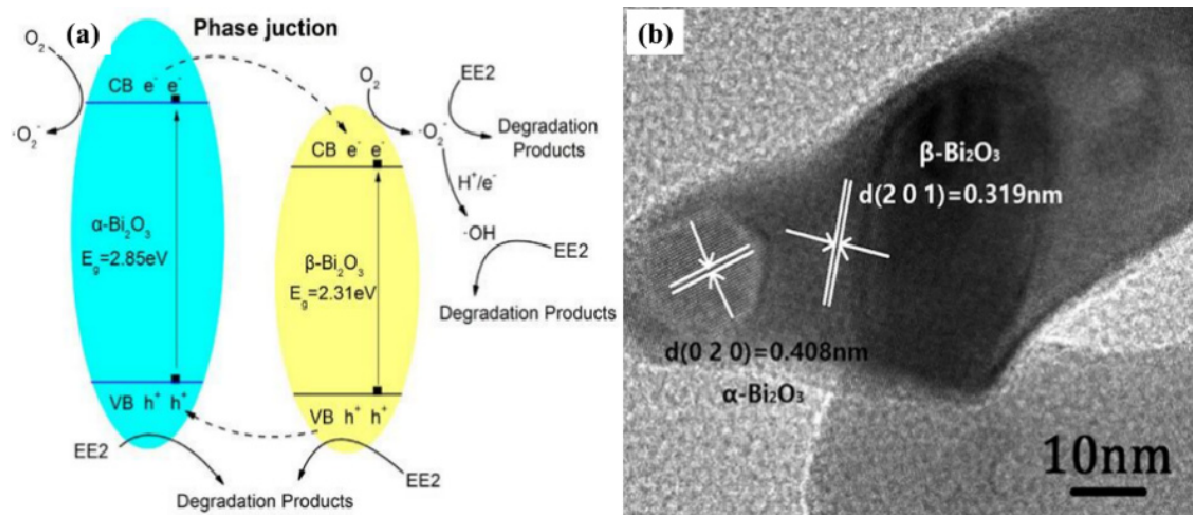

Fig. 4. (a) Photocatalytic mechanism and (b) the HRTEM images of the $\alpha / \beta-\mathrm{Bi}_{2} \mathrm{O}_{3}$ photocatalyst. Reprinted with permission from Ref. [59]. Copyright 2017 Elsevier. 
synthesized the $\alpha / \beta-\mathrm{Bi}_{2} \mathrm{O}_{3}$ homojunction photocatalyst with the use of novel solvothermal-calcination or one-pot hydrothermal methods. Correspondingly, the material exhibited exceptional and synergistic photocatalytic activity and a fairly stable performance for the removal of $17 \alpha$-ethinylestradiol and rhodamine B from aqueous solutions. Fig. 4 shows a possible photocatalytic mechanism and a clear phase junction between $\alpha-\mathrm{Bi}_{2} \mathrm{O}_{3}$ and $\beta-\mathrm{Bi}_{2} \mathrm{O}_{3}$. It suggests that the approach is practicable toward the design and construction of heterogeneous photocatalysts. Because of the different electronic structures of the layered $2 \mathrm{H} / 1 \mathrm{~T}-\mathrm{MoS}_{2}$ with the semiconducting $2 \mathrm{H}$ (trigonal prismatic D3h) phase and the $1 \mathrm{~T}$ (octahedral Oh) metallic phase, $\mathrm{Wu}$ et al. [148] reported earth-abundant $1 \mathrm{~T}-\mathrm{MoS}_{2}$ and graphitic $\mathrm{C}_{3} \mathrm{~N}_{4}$ heterojunctions formed by a facile hydrothermal method in thioacetamide and molybdenum pentachloride. These allowed faster photogeneration of electrons for a drastically improved photocatalytic hydrogen evolution activity compared to that of the $2 \mathrm{H}$ counterpart (Fig. 5). Furthermore, mixed-phase $\mathrm{TiO}_{2}$ powders with controllable anatase/rutile ratios could be easily controlled by the hydrothermal or solvothermal method, such as the $\mathrm{pH}[149,150]$, solvent type [151], and precursor [152]. For instance, Li et al. [149] reported anatase and rutile mixed-phase $\mathrm{TiO}_{2}$ photocatalysts by the tartaric acid as a phase regulator in the hydrothermal environment and found that the heterojunction catalyst with an anatase to rutile content ratio of $77 \%$ to $23 \%$ exhibited the highest photocatalytic activity. Li et al. [152] also prepared under controlled conditions a pure phase and mixtures of four $\mathrm{TiO}_{2}$ pol- ymorphs (anatase, rutile, brookite, and $\mathrm{TiO}_{2}(\mathrm{~B})$ ) based on hydrothermal reactions in an acidic potassium titanate solution as the precursor. In Fig. 6, the acid concentrations of the $\mathrm{HCl}$, $\mathrm{HNO}_{3}$, and $\mathrm{H}_{2} \mathrm{SO}_{4}$ solutions can change the compositions of the mixed-phase anatase $/ \mathrm{TiO}_{2}(\mathrm{~B})$, rutile/brookite, and $\mathrm{TiO}_{2}(\mathrm{~B}) /$ rutile/rookite hierarchical nanostructures. Accordingly, the samples with 59\% anatase were obtained and led to the highest photocatalytic activity, which was 1.43 times that of P25. Similarly, Sun et al. [153] fabricated the heterostructured $\mathrm{Bi}_{2} \mathrm{O}_{2} \mathrm{CO}_{3} / \mathrm{Bi}_{2} \mathrm{O}_{4}$ photocatalysts by a facile one-pot hydrothermal method, where $\mathrm{Bi}_{2} \mathrm{O}_{4}$ nanorods and particles were deposited on the surfaces of the $\mathrm{Bi}_{2} \mathrm{O}_{2} \mathrm{CO}_{3}$ plates, and the material exhibited remarkably enhanced activity compared to $\mathrm{Bi}_{2} \mathrm{O}_{2} \mathrm{CO}_{3}$ and $\mathrm{Bi}_{2} \mathrm{O}_{4}$.

\subsubsection{Controlling calcination-induced phase junctions}

When the semiconductors were heated, the atoms or ions in the lattices vibrated violently and broke away from the original lattice to form new nuclei. They gradually grew by accepting diffused material flow. The main factors that affected semiconductor phase transitions were the crystal structure, internal defects, morphology (particle size, porosity, and surface condition), energy state of components, as well as the heating temperature, time, and atmosphere. According to this phenomenon, a theoretical model of semiconductor phase transition is proposed to construct the heterojunction, as shown in Fig. 7 [123]. Herein, owing to the control of thermodynamics and phase transition kinetics, the phase transition of semiconduc-
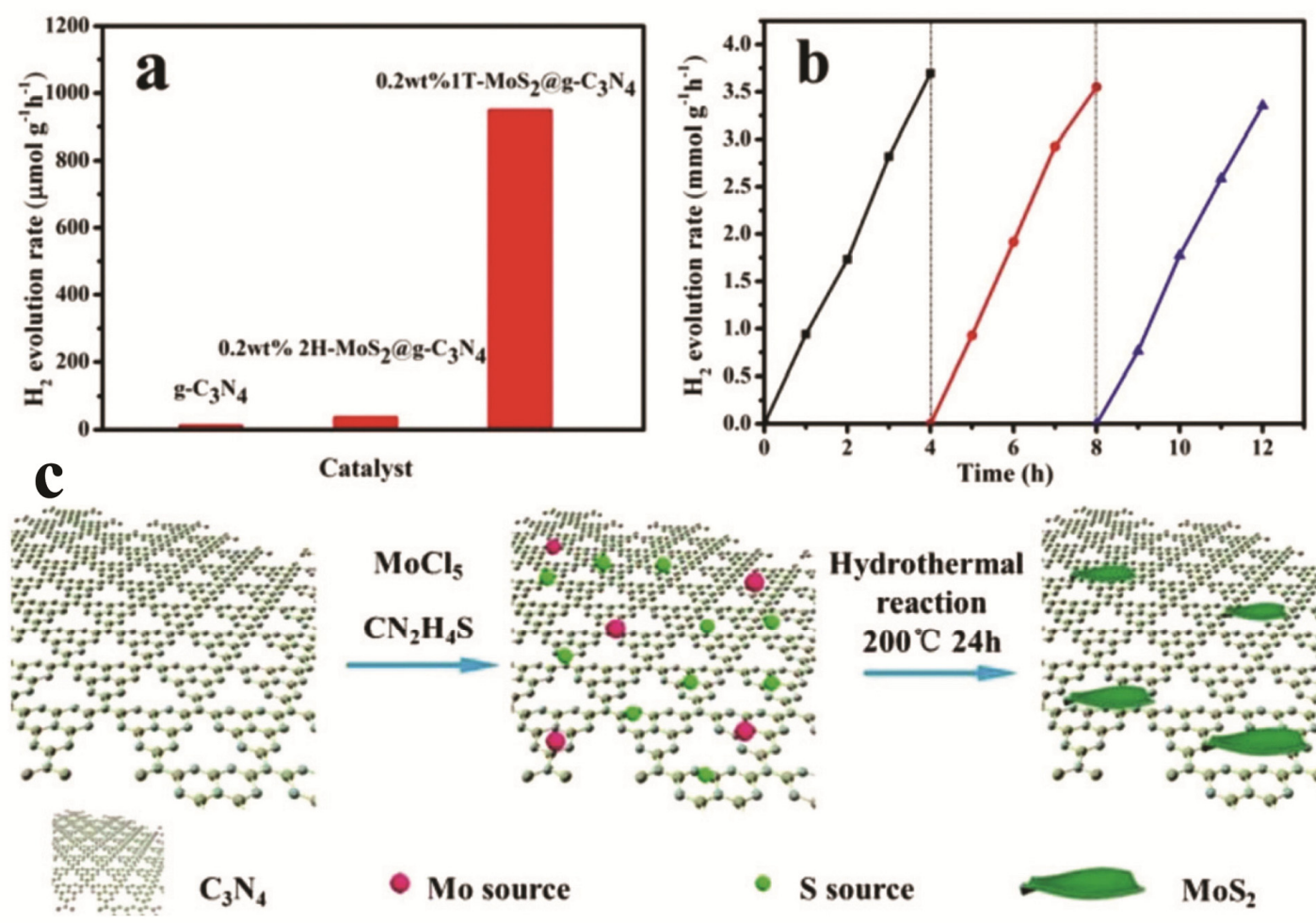

Catalyst Time (h)
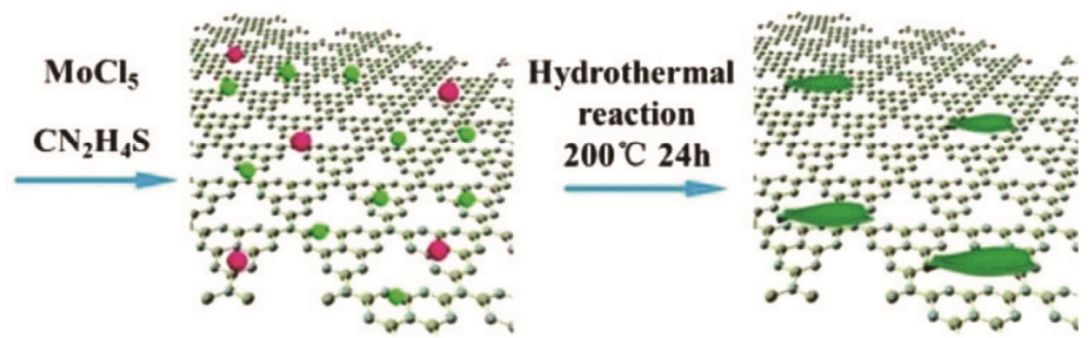

- Mo source

- S source

$\mathrm{MoS}_{2}$

Fig. 5. (a) Photocatalytic hydrogen production rates for g- $\mathrm{C}_{3} \mathrm{~N}_{4}$ and 0.20 wt $\% 2 \mathrm{H}-\mathrm{MoS}_{2} @ g-\mathrm{C}_{3} \mathrm{~N}_{4}$ nanosheets and 0.20 wt $\% 1 \mathrm{~T}-\mathrm{MoS} @$ g- $\mathrm{C}_{3} \mathrm{~N}_{4}$ nanosheets; (b) Stability test outcomes of $0.20 \mathrm{wt} \% 1 \mathrm{~T}-\mathrm{MoS}_{2} @ g-\mathrm{C}_{3} \mathrm{~N}_{4}$ nanosheets over a period of $12 \mathrm{~h}$ in $4 \mathrm{~h}$ cycles; (c) Schematics showing the synthetic process of the 1T-MoS $@ g-C_{3} N_{4}$ nanosheets. Reprinted with permission from Ref. [148]. Copyright 2017 Royal Society of Chemistry. 

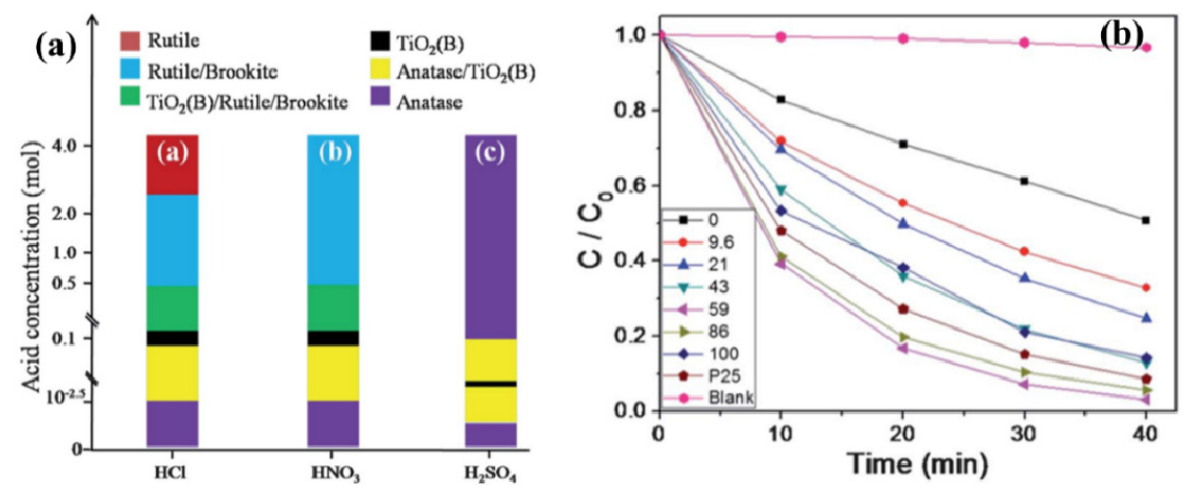

Fig. 6. (a) Phase diagram of $\mathrm{TiO}_{2}$ samples prepared in $\mathrm{HCl}, \mathrm{HNO}_{3}$, and $\mathrm{H}_{2} \mathrm{SO}_{4}$ solutions based on hydrothermal reactions; (b) Photocatalytic activities of the samples with different anatase contents and P25 for MB decomposition. Reprinted with permission from Ref. [152]. Copyright 2012 Royal Society of Chemistry.

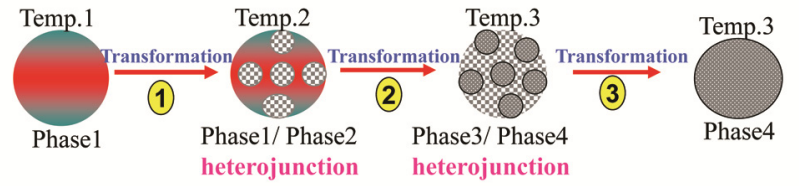

Fig. 7. Theoretical model of semiconductor phase transition explaining the construction of heterojunctions.

tors usually occurs in a step-by-step manner. When the temperature of the system rises to Temp. 1, the first phase transition takes place in the semiconductor. By controlling the phase transition rate, a two-phase coexistence system can be obtained. Because the phase transition occurs within itself, phases 1 and 2 can generate close contact heterostructures, and the heterostructures of the crystal phase 2 /crystal phase 3 or crystal phase $3 /$ crystal phase 4 may also be formed. Once the appropriate amount of heterogeneous phase structure is successfully constructed, a potential difference may exist between the two types of semiconductor crystal phases with energy level matching, which will establish an internal electric field, accelerate the separation of photogenerated electrons and holes, and improve the activity and stability of the photocatalytic reaction.

For instance, our group constructed binary $[123,124]$ and ternary $[154,155]$ semiconductor phase formation systems with heterogeneous phase junctions based on thermodynamics and phase transformation kinetics, and found the regulation of the crystal phase interface on photoelectrons $\left(\mathrm{e}^{-}\right)$and holes $\left(h^{+}\right)$. Thereinto, the phase transition law of $\mathrm{Ag}_{2} \mathrm{CO}_{3}$ was found, and the mechanism of phase transition was established to construct $\mathrm{Ag}_{2} \mathrm{CO}_{3} @ \mathrm{Ag}_{2} \mathrm{O}$. Thus, the silver-based photocatalyst was obtained with high-stability and high-photocatalytic efficiency, which established $\mathrm{Ag}_{2} \mathrm{CO}_{3}$ as a hotspot photocatalyst in recent years. Thermogravimetric analyses in Fig. 8a show that the weightlessness in the temperature range of 180 to $250{ }^{\circ} \mathrm{C}$ corresponds to the phase transition of $\mathrm{Ag}_{2} \mathrm{CO}_{3} \rightarrow \mathrm{Ag}_{2} \mathrm{O}$. Meanwhile, the $\mathrm{Ag}_{2} \mathrm{O}$ phase was stable in the temperature range of 250 to $300^{\circ} \mathrm{C}$, and the $\mathrm{Ag}_{2} \mathrm{O} \rightarrow \mathrm{Ag}$ phase transition corresponded to the temperature range of 300 to $425^{\circ} \mathrm{C}$. Fig. $8 \mathrm{~b}$ shows that the
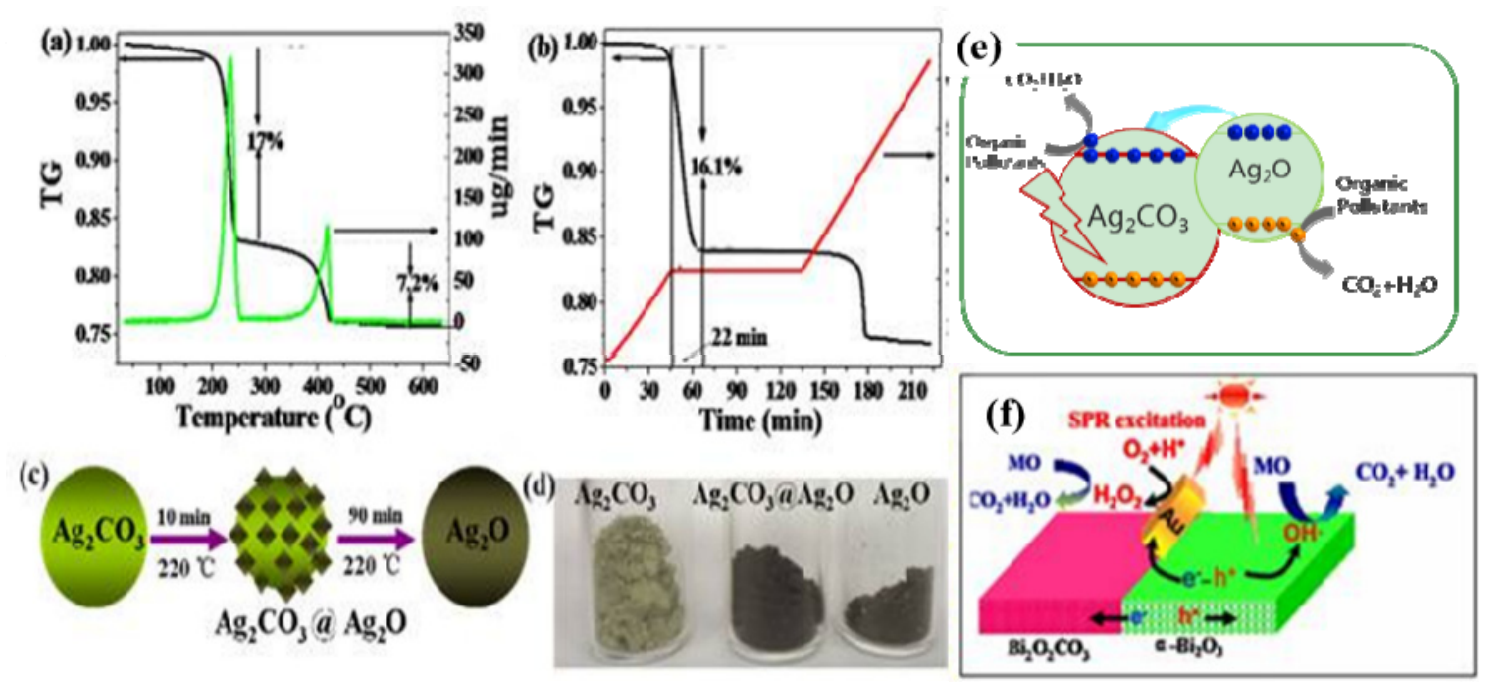

Fig. 8. (a, b) TG curves of $\mathrm{Ag}_{2} \mathrm{CO}_{3}$ in air atmosphere; (c) Schematic of the $\mathrm{Ag}_{2} \mathrm{CO}_{3} @ \mathrm{Ag}_{2} \mathrm{O}$ heterostructure according to the $\mathrm{Ag}_{2} \mathrm{CO}_{3}$ phase transition; (d) Photograph showing the color changes of different samples; (e) Energy-level structure of $\mathrm{Ag}_{2} \mathrm{CO}_{3} @ \mathrm{Ag}_{2} \mathrm{O}$; (f) Electron and hole transfer model diagram showing the surface plasmon resonance effect. Reprinted with permission from Refs. [123,124]. Copyright 2014 Wiley and 2016 Elsevier. 
production of the $\mathrm{Ag}_{2} \mathrm{CO}_{3}$ phase transition was completely dependent on $\mathrm{Ag}_{2} \mathrm{O}$ at $210{ }^{\circ} \mathrm{C}$ and occurred over a period of 22 min. The $\mathrm{Ag}_{2} \mathrm{CO}_{3}$ surface began to change into $\mathrm{Ag}_{2} \mathrm{O}$ when it was heated, and the new phase of $\mathrm{Ag}_{2} \mathrm{O}$ was wrapped on the $\mathrm{Ag}_{2} \mathrm{CO}_{3}$ surface, which prevented the escape of $\mathrm{CO}_{2}$ and the $\mathrm{Ag}_{2} \mathrm{O}$ crystal growth and reduced the phase transition rate. The existence of the $\mathrm{Ag}_{2} \mathrm{CO}_{3} @ \mathrm{Ag}_{2} \mathrm{O}$ heterocrystalline interface was confirmed by HRTEM. Therefore, the core-shell structure of $\mathrm{Ag}_{2} \mathrm{CO}_{3} @ \mathrm{Ag}_{2} \mathrm{O}$ at different phase contents could be prepared by accurately controlling the heating parameters of $\mathrm{Ag}_{2} \mathrm{CO}_{3}$. The calculation of electronegativity proved that the constructed $\mathrm{Ag}_{2} \mathrm{CO}_{3} @ \mathrm{Ag}_{2} \mathrm{O}$ had a matching energy level structure (Fig. 8e) that can generate an internal electric field. With the use of visible light irradiation, the photogenerated holes of $\mathrm{Ag}_{2} \mathrm{CO}_{3}$ could easily migrate to the $\mathrm{Ag}_{2} \mathrm{O}$ valence band, while the electron of $\mathrm{Ag}_{2} \mathrm{O}$ could move to the conduction band of $\mathrm{Ag}_{2} \mathrm{CO}_{3}$, thereby accelerating the separation of $\mathrm{h}^{+}$and $\mathrm{e}^{-}$. Based on the surface plasmon resonance effect of precious metals (Fig. 8e), $\mathrm{Au}, \mathrm{Ag}, \mathrm{Au}$, and $\mathrm{Pt}$ nanoparticles were deposited on the heterogeneous boundary plane and the activity of photocatalytic reaction was further improved [154].

The $\mathrm{Ag}_{2} \mathrm{CO}_{3} @ \mathrm{Ag}_{2} \mathrm{O}$ heterojunction interface has increased the photocatalytic degradation efficiency for organic pollutants, such as dyes, phenol, bisphenol A, and others. In the presence of visible light irradiation, the photocatalytic activity of the highly concentrated methyl orange dye can be completely degraded with mineralization. The efficiency of $\mathrm{Ag}_{2} \mathrm{CO}_{3} @ \mathrm{Ag}_{2} \mathrm{O}$ is 67 times and 31 times higher than those of $\mathrm{Ag}_{2} \mathrm{CO}_{3}$ and $\mathrm{Ag}_{2} \mathrm{O}$, respectively, and is much higher than that of the novel $\mathrm{Ag}_{3} \mathrm{PO}_{4}$ photocatalyst [24]. A silver-based photocatalyst is used as a noble metal photocatalyst and has a high cost in engineering applications. Additionally, the silver ion of the binary heterojunction photocatalyst may be reduced to a simple mass by the photogenerated electrons produced by itself during the reaction process. Accordingly, the active component may be lost. Meanwhile, a $\mathrm{Zn}_{3}\left(\mathrm{VO}_{4}\right)_{2} / \mathrm{Zn}_{2} \mathrm{~V}_{2} \mathrm{O}_{7} / \mathrm{ZnO}$ ternary and cheap zinc vanadate photocatalyst system has been developed [155] whose photocatalytic activity was much higher than that of the $\mathrm{Zn}_{3}(\mathrm{OH})_{2} \mathrm{~V}_{2} \mathrm{O}_{7} \cdot 2 \mathrm{H}_{2} \mathrm{O}$ precursor synthesized with the use of the microwave hydrothermal synthesis and the $\mathrm{Zn}_{2} \mathrm{~V}_{2} \mathrm{O}_{7}$ monoclinic system calcined at $800{ }^{\circ} \mathrm{C}$. The thermodynamic calculation shows that $\mathrm{Zn}_{3}(\mathrm{OH})_{2} \mathrm{~V}_{2} \mathrm{O}_{7} \cdot 2 \mathrm{H}_{2} \mathrm{O}$ is a step-by-step phase transition material $\left(\mathrm{Zn}_{3}(\mathrm{OH})_{2} \mathrm{~V}_{2} \mathrm{O}_{7} \cdot 2 \mathrm{H}_{2} \mathrm{O} \rightarrow \mathrm{Zn}_{3}\left(\mathrm{VO}_{4}\right)_{2} / \mathrm{Zn}_{2} \mathrm{~V}_{2} \mathrm{O}_{7} / \mathrm{ZnO}\right.$ $\rightarrow \mathrm{Zn}_{2} \mathrm{~V}_{2} \mathrm{O}_{7}$ ), as shown in Fig. 9a. The double Z-scheme mechanism in Fig. 9b shows the nontraditional transport of photo-induced $\mathrm{h}^{+}$and $\mathrm{e}^{-}$for the efficient removal of the pollutants.

Based on this principle, more types of bismuth-based heterogeneous phase junction catalysts were developed with increased photocatalytic performance, such as $\mathrm{BiOI} / \mathrm{Bi}_{5} \mathrm{O}_{7} \mathrm{I}$, $\mathrm{Bi}_{5} \mathrm{O}_{7} \mathrm{I} / \mathrm{Bi}_{2} \mathrm{O}_{3}, \quad \mathrm{BiOBr} / \mathrm{Bi}_{24} \mathrm{O}_{31} \mathrm{Br}$, and $\mathrm{Bi}_{24} \mathrm{O}_{31} \mathrm{Br} / \alpha-\mathrm{Bi}_{2} \mathrm{O}_{3}$ [156-158]. Other thermodynamically unstable substances, such as other series of heterogeneous photocatalysts of silver-based semiconductors, bismuth oxyhalides, bismuth oxide, and bismuth carbonate, were systematically investigated by other groups [116,159-162]. For example, Huang et al. [164] prepared three-dimensional hierarchical bismuth oxyiodides with an in situ phase transformation process based on a controlled calcination strategy. Accordingly, BiOI microspheres were used as a self-sacrificed template for the construction of the phase junctions, while the formation diagram of the hierarchical $\mathrm{Bi}_{4} \mathrm{O}_{5} \mathrm{I}_{2}-\mathrm{Bi}_{5} \mathrm{O}_{7} \mathrm{I}$ hetero architecture was obtained as shown in Fig. 10. The authors confirmed that the activity order was $\mathrm{Bi}_{4} \mathrm{O}_{5} \mathrm{I}_{2}-\mathrm{Bi}_{5} \mathrm{O}_{7} \mathrm{I}>\mathrm{Bi}_{4} \mathrm{O}_{5} \mathrm{I}_{2}>\mathrm{Bi}_{5} \mathrm{O}_{7} \mathrm{I}>\mathrm{BiOI}$, which ascribed to the efficient charge separation and transfer that originated from band alignment of the as-formed phase junction. Hou et al. [165] prepared an $\alpha-\beta$ phase $\mathrm{Bi}_{2} \mathrm{O}_{3}$ nanowire heterojunction by a facile hydrothermal that was responsive to visible light, and the following heat treatment process and the reaction temperature could readily tailor the ratio of the monoclinic $\alpha-\mathrm{Bi}_{2} \mathrm{O}_{3}$ and the tetragonal $\beta-\mathrm{Bi}_{2} \mathrm{O}_{3}$, and adjust the morphology from two-dimensional $\beta-\mathrm{Bi}_{2} \mathrm{O}_{3}$ sheets to the $\alpha-/ \beta-\mathrm{Bi}_{2} \mathrm{O}_{3}$ nanowire junction. The $\alpha-/ \beta-\mathrm{Bi}_{2} \mathrm{O}_{3}$ heterojunction had an exceptional photocatalytic performance compared to that of the $\beta-\mathrm{Bi}_{2} \mathrm{O}_{3}$ sheets in the degradation of rhodamine $\mathrm{B}$ and methyl orange in the presence of visible light irradiation that was attributed to the efficient charge separation and transfer. Bian et al. [126] fabricated $\quad \mathrm{B}-\mathrm{Bi}_{2} \mathrm{O}_{3} / \mathrm{Bi}_{2} \mathrm{O}_{2.33} @ \mathrm{Bi}_{2} \mathrm{O}_{2} \mathrm{CO}_{3}$ ternary composites based on the self-integration of the slow, thermal decomposi-
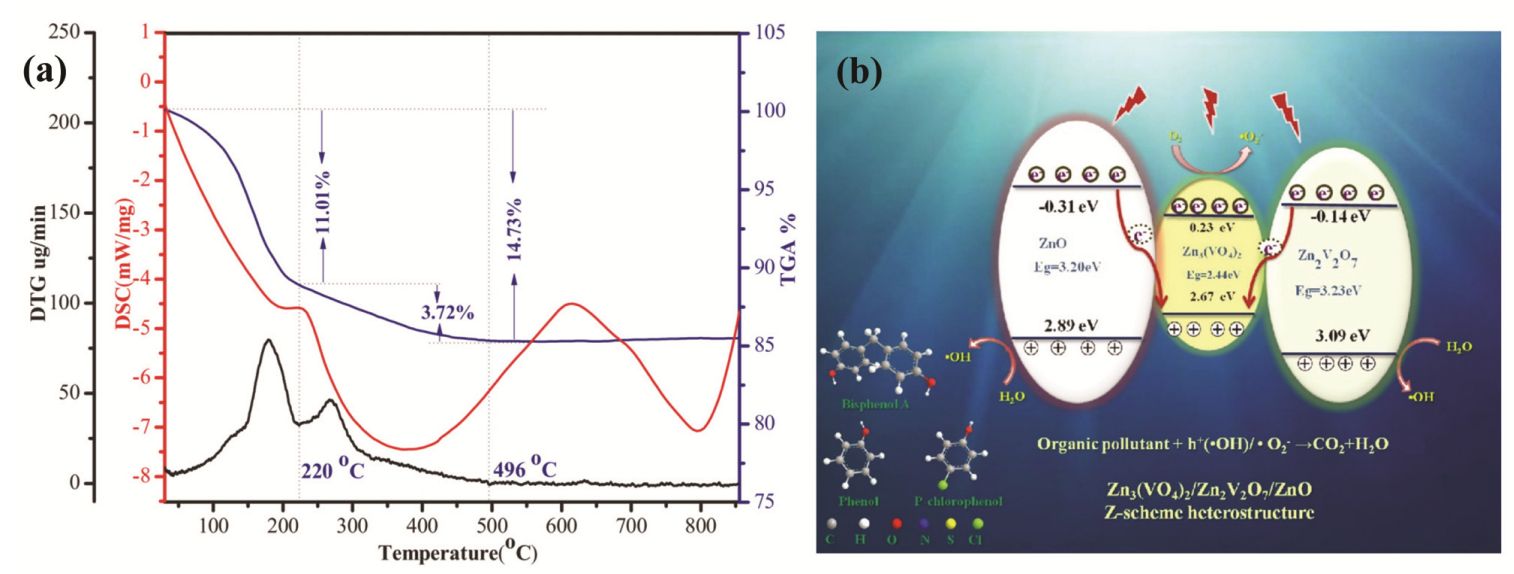

Fig. 9. (a) Construction of the $\mathrm{Zn}_{3}\left(\mathrm{VO}_{4}\right)_{2} / \mathrm{Zn}_{2} \mathrm{~V}_{2} \mathrm{O}_{7} / \mathrm{ZnO}$ ternary heterojunction according to the thermal analysis of $\mathrm{Zn}_{3}(\mathrm{OH})_{2} \mathrm{~V}_{2} \mathrm{O}_{7} \cdot 2 \mathrm{H}_{2} \mathrm{O}$; (b) Possible photocatalytic process of organic pollutants over the $\mathrm{Zn}_{3}\left(\mathrm{VO}_{4}\right)_{2} / \mathrm{Zn}_{2} \mathrm{~V}_{2} \mathrm{O}_{7} / \mathrm{ZnO}$ system. Reprinted with permission from Ref. [155]. Copyright 2018 Elsevier. 

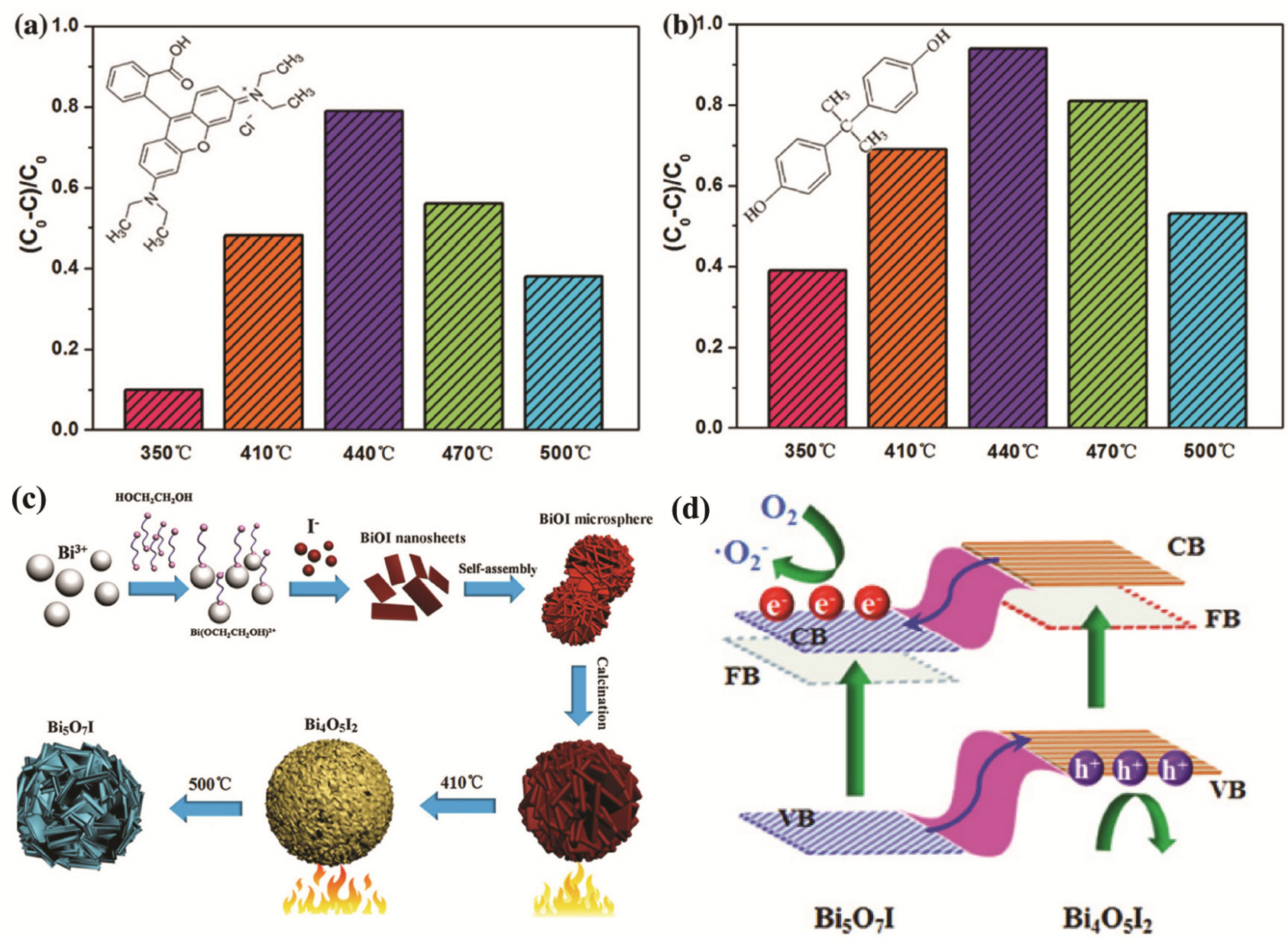

Fig. 10. Photodegradation efficiency of (a) RhB and (b) BPA over calcinated BiOI at different temperatures; (c) Formation diagram of the hierarchical architectures; (d) $\mathrm{Bi}_{4} \mathrm{O}_{5} \mathrm{I}_{2}-\mathrm{Bi}_{5} \mathrm{O}_{7} \mathrm{I}$ phase junction. Reprinted with permission from Ref. [164]. Copyright 2017 Elsevier.

tion of $\mathrm{Bi}_{2} \mathrm{O}_{2} \mathrm{CO}_{3}$. Equivalently, $\mathrm{Bi}_{2} \mathrm{O}_{2} \mathrm{CO}_{3} \rightarrow$ $\beta-\mathrm{Bi}_{2} \mathrm{O}_{3} / \mathrm{Bi}_{2} \mathrm{O}_{2.33} @ \mathrm{Bi}_{2} \mathrm{O}_{2} \mathrm{CO}_{3}\left(300{ }^{\circ} \mathrm{C}\right) \rightarrow \beta-\mathrm{Bi}_{2} \mathrm{O}_{3} / \mathrm{Bi}_{2} \mathrm{O}_{2.33}\left(320{ }^{\circ} \mathrm{C}\right)$ $\rightarrow \quad \beta-\mathrm{Bi}_{2} \mathrm{O}_{3} \quad\left(350 \quad{ }^{\circ} \mathrm{C}\right)$. It was found that $\beta-\mathrm{Bi}_{2} \mathrm{O}_{3} / \mathrm{Bi}_{2} \mathrm{O}_{2.33} @ \mathrm{Bi}_{2} \mathrm{O}_{2} \mathrm{CO}_{3}$ had a well-matched bandgap and displayed superior photocatalytic performance compared to $\mathrm{Bi}_{2} \mathrm{O}_{2} \mathrm{CO}_{3}$.

In addition, other heterogeneous phase junction catalysts were evaluated. For example, Zeng et al. [166] constructed a $\mathrm{Sr}_{2} \mathrm{Ta}_{2} \mathrm{O}_{7-x} \mathrm{~N}_{x} / \mathrm{SrTaO}_{2} \mathrm{~N}$ heterostructured photocatalyst in situ using hydrothermally prepared $\mathrm{Sr}_{2} \mathrm{Ta}_{2} \mathrm{O}_{7}$ nanosheets in the atmosphere of $\mathrm{NH}_{3}$, thereby achieving a well-matched band structure. In the photocatalytic hydrogen evolution, the $\mathrm{Sr}_{2} \mathrm{Ta}_{2} \mathrm{O}_{7-x} \mathrm{~N}_{x} / \mathrm{SrTaO}_{2} \mathrm{~N}$ heterostructured photocatalyst yielded the highest rate with $\mathrm{Sr}_{2} \mathrm{Ta}_{2} \mathrm{O}_{7-x} \mathrm{~N}_{x}$ and pure $\mathrm{SrTaO}_{2} \mathrm{~N}$ using similar reaction conditions. Wang et al. [109] first investigated the $\alpha-\beta \mathrm{Ga}_{2} \mathrm{O}_{3}$ phase junction by phase transformation at elevated temperatures from 673 to $1073 \mathrm{~K}$. Furthermore, they demonstrated that in photocatalytic water splitting, the $\mathrm{Ga}_{2} \mathrm{O}_{3}$ phase junction calcined at a temperature range of 863-893 K had a much higher activity than the pure $\alpha$ phase (673 to 773 $\mathrm{K}$ ) or the $\beta$ phase ( 973 to $1073 \mathrm{~K}$ ) of $\mathrm{Ga}_{2} \mathrm{O}_{3}$.

On the basis of phase transitions, the mechanism of phase transition and the co-doping of elements used to improve pho- tocatalytic performance were further explored. For example, $\mathrm{Ti}_{2} \mathrm{CN}$ was used for the first time as a raw material, and C-N self-doping was realized at the same time by the precise control of the $\mathrm{O}_{2}$ atmosphere, heating time, and temperature, in the reactions relevant to the formation of the crystal phase of anatase and rutile $\mathrm{TiO}_{2}$ [167]. The photoelectron spectra indicated that $\mathrm{C}$ and $\mathrm{N}$ were doped in the process of the phase transition. It was further proved that $\mathrm{C}-\mathrm{N} / \mathrm{TiO}_{2}$ could be prepared with different $\mathrm{C}$ and $\mathrm{N}$ contents based on the accurate control of the heating temperature, time, and atmosphere of $\mathrm{Ti}_{2} \mathrm{CN}$. C-N codoping can form impurity energy levels, reduce the gap of $\mathrm{TiO}_{2}$, accelerate the separation of $\mathrm{h}^{+}$and $\mathrm{e}^{-}$, and improve the absorption ability. Additionally, the preparation of $\mathrm{P}$ and $\mathrm{WO}_{3}$ co-doped $\mathrm{TiO}_{2}$ can significantly inhibit the photogenerated electron and hole recombination [168]. Zhu et al. [169] investigated the effects of heat treatment on the anatase-rutile phase transformation and the photocatalytic activity of Sn-doped $\mathrm{TiO}_{2}$ nanomaterials. It is found that at $350{ }^{\circ} \mathrm{C}, 1 \% \mathrm{Sn}$ doping led to the highest degradation rate, while at $500{ }^{\circ} \mathrm{C}$ and $650{ }^{\circ} \mathrm{C}, 5 \% \mathrm{Sn}$ doping led to the best photocatalytic activity. The relationship between the regulation of heterogeneous phase junctions and the physical properties of the compounds, such as the crystal structure, morphology, ionic radius, and decomposition kinet- 
ics, were also investigated. Therefore, the highly efficient heterojunction photocatalyst was synthesized by the phase transformation kinetics method of heating and self-transformation. This constitutes the technological innovation of the preparation process of the heterojunction photocatalyst, whereby the quality of the photocatalyst has been improved.

\subsubsection{Self-surface phase junctions of crystal plane}

In a photocatalytic reaction on the surface of a semiconductor, it is essential to achieve an effective transfer and spatial separation of the photoinduced charges on the surface of the photocatalyst [170]. Thereinto, the surface phase junctions and the aligned built-in electric fields can drive the charge separation and transfer [171-173]. The outcome of this process is the formation of two spatially separated surface locations that boost the targeted chemical reaction. Therefore, the self-surface phase junction of a single semiconductor underlines the role of the built-in electric field in conducting the semiconductor carriers to the surface redox reaction sites.

Using effective detection technology, Li et al. [57] developed ultraviolet (UV) Raman spectroscopy in the study of the surface properties of the $\mathrm{TiO}_{2}$ catalyst, which has recently proved to be a powerful tool in determining the variation of the surface phase structure. Because UV Raman spectroscopy can be more sensitive to the surface phase, it can overcome the interference of fluorescence and strengthen the Raman signals at short wavelengths. Li's group [143] also investigated the influence of $\mathrm{Nd}_{2} \mathrm{O}_{3}$ on the surface phase of $\mathrm{TiO}_{2}$ using UV Raman spectroscopy and showed that the coexistence of anatase and rutile in the surface region of $\mathrm{Nd}^{-} \mathrm{TiO}_{2}$ determined the optimal activity. UV Raman spectra certainly justified the fact that the surface ion $\mathrm{SO}_{4}{ }^{2-}$ could restrain the surface phase transformation at elevated temperatures [145].

Based on the hydrothermal treatment strategy in the $\mathrm{HNO}_{3}$ solution using titanate nanotube as a precursor, Huang et al. [174] synthesized the highly active $\mathrm{TiO}_{2}$ photocatalysts of the anatase-brookite and anatase-rutile surface phase junction. The surface heterophase junctions of $\mathrm{TiO}_{2}$ could suppress the recombination of photoinduced charge carriers. Additionally, $\mathrm{TiO}_{2}$ consisted of $72.9 \mathrm{wt} \%$ anatase, $24.6 \mathrm{wt} \%$ brookite, and 2.5 wt $\%$ rutile, and exhibited a higher photocatalytical activity owing to the $\mathrm{H}_{2}$ yield than that of P25 using the same reaction conditions ( $179 \mu \mathrm{mol} \mathrm{h}^{-1} \mathrm{~g}^{-1}$ vs. $\left.45.3 \mu \mathrm{mol} \mathrm{h}^{-1} \mathrm{~g}^{-1}\right)$.

According to the density functional theory (DFT), Yu et al. [172] calculated the density of states on different crystal planes of anatase $\mathrm{TiO}_{2}$. It was found that the (001) and the (101) planes can form heterojunctions of crystal planes and promote the separation and transfer of photogenerated electrons and holes (Fig. 11(a)). The results of the photocatalytic reduction of $\mathrm{CH}_{4}$ by $\mathrm{CO}_{2}$ show that when the ratio of the (101) and (001) surfaces exposed to $\mathrm{TiO}_{2}$ is close to $1: 1$ (optimum ratio), the photogenerated electrons gathered on the (101) plane could participate in the reduction reaction, while holes gathered on the (001) plane could participate in the oxidation reduction. The formation rate of $\mathrm{CH}_{4}$ reached $1.35 \mu \mathrm{mol} \mathrm{h}^{-1} \mathrm{~g}^{-1}$ and increased 21 times.

In recent years, Li et al. [175] also indicated that the pho-

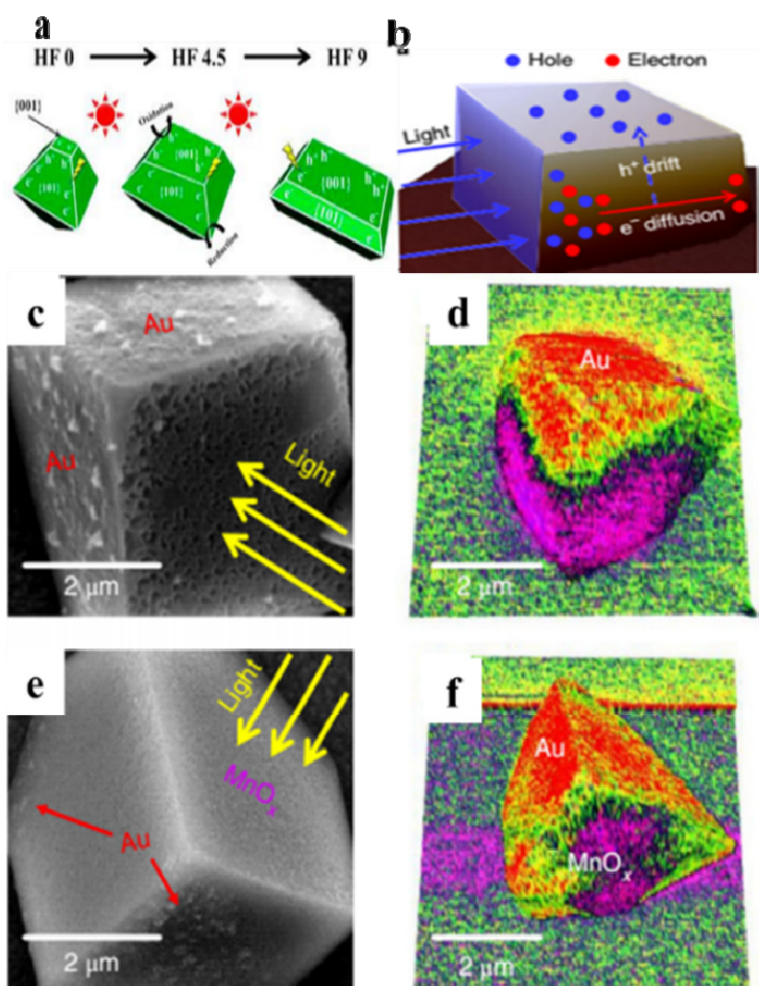

Fig. 11. (a) Spatial separation of redox sites of the exposed (101) and (001) facets on $\mathrm{TiO}_{2}$; (b) Charge separation on the (001) facet of $\mathrm{Cu}_{2} \mathrm{O}$ parallel to the light irradiation direction; SEM images of (c) Au-deposited $\left(\mathrm{Cu}_{2} \mathrm{O} / \mathrm{Au}\right)$ and (d) dual co-catalyst deposited $\left(\mathrm{Cu}_{2} \mathrm{O} / \mathrm{Au} / \mathrm{MnO}_{x}\right) \mathrm{Cu}_{2} \mathrm{O}$ crystals prepared via photodeposition with the use of asymmetric illumination; SPVM images of (e) Au-deposited and (f dual co-catalyst-deposited $\mathrm{Cu}_{2} \mathrm{O}$ crystals obtained with the use of asymmetric illumination. Reprinted with permission from Refs. [60,61]. Copyright 2014 American Chemical Society and 2018 Nature.

to-induced surface potential changes (SPV) could be imaged directly to assess the localized spatial charge separation behavior across the spatially varying charge regions at the surfaces of the photocatalysts. The same authors were able to identify complex charge separation and transfer processes that have been revealed in many other photocatalysts [176,177]. For instance, single cubic $\mathrm{Cu}_{2} \mathrm{O}$ crystals were prepared to reveal the influence of the intrinsic asymmetric built-in electric field on charge separation by localized SPV measurements [61]. The (001) facet was exposed to the light direction (Fig. 11(b)), and the charge separation was driven by the built-in electric field with a SPV of $20 \mathrm{mV}$. The quantitative results showed that the photogenerated charge separation was highly dependent on the length of $\mathrm{Cu}_{2} \mathrm{O}$ (i.e., the particle size), whereby holes moved toward the illuminated facet, and electrons moved toward the shadow facet. It can be deduced that the heterojunction of the crystal plane of cubic $\mathrm{Cu}_{2} \mathrm{O}$ particles under asymmetric illumination was important in the photocatalyst system. The spatially separated electrons and holes were available for surface redox reactions of trivalent $\mathrm{Au}^{3+}$ reduction and $\mathrm{Mn}^{2+}$ oxidation, as shown by Fig. 11(c) and (d), whereby the shadow facets included the deposition of Au particles and the illuminated facets contained the $\mathrm{MnO}_{x}$ agglomerates. The charge separation behavior was also further confirmed by SPV, as shown in Fig. 


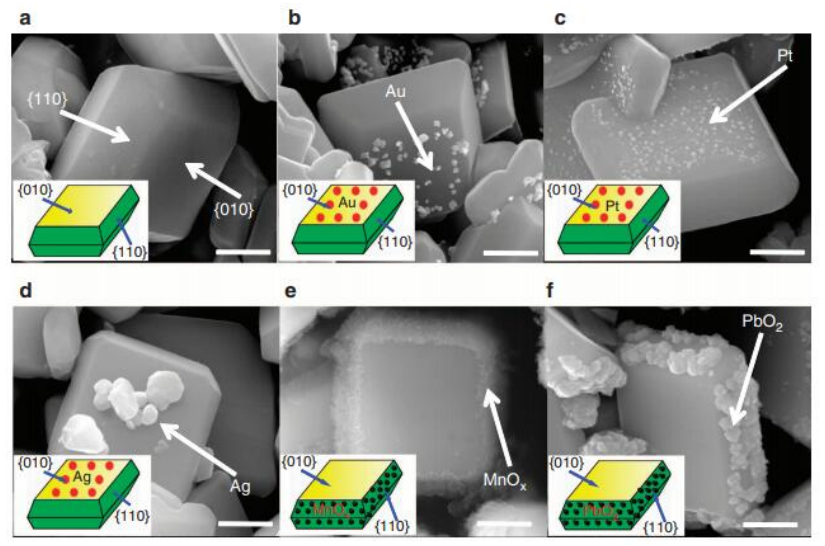

Fig. 12. SEM images of $\mathrm{BiVO}_{4}$ with and without the deposition of single metal/oxide. (a) $\mathrm{BiVO}_{4}$, (b) $\mathrm{Au} / \mathrm{BiVO}_{4}$, (c) $\mathrm{Pt} / \mathrm{BiVO}_{4}$, (d) $\mathrm{Ag} / \mathrm{BiVO}_{4}$, (e) $\mathrm{MnO}_{x} / \mathrm{BiVO}_{4}$, (f) $\mathrm{PbO}_{2} / \mathrm{BiVO}_{4}$. The contents of the deposited metals/metal oxides are all $5 \mathrm{wt} \%$. Scale bar, $500 \mathrm{~nm}$. Reprinted with permission from Ref. [176]. Copyright 2013 Nature.

\section{1(e) and (f).}

Similarly, in Fig. 12, also shown are the spatial separations of the photogenerated electrons and holes on the (010) and (110) crystal facets of $\mathrm{BiVO}_{4}[60,168,177]$. The reduction reaction of the photogenerated electrons and the oxidation reaction of the photogenerated holes can occur on the (010) and (110) facets of $\mathrm{BiVO}_{4}$ and correspond to the selective deposition of the $\mathrm{Pt}$ and $\mathrm{MnO}_{x}$ cocatalysts. These results demonstrate that a material with appropriate self-phase-junction of crystal planes is vitally important in the photocatalytic system. This also provides guidance in designing different, high-energy crystal planes for efficient charge separation and redox reactions in energy and in environmental photocatalysis.

\subsubsection{Other assistant-driven phase junctions}

To-this-date, other empirical and experimental methods have also been reported for the construction of phase junctions, such as electrochemistry, pulse laser irradiation or UV/ozone-driving, mechanical alloying, and pressure-induced phase transitions. Using electrochemical methods, Liang et al. [179] prepared a mixture of anatase and rutile phases with $\mathrm{TiO}_{2}$ nanotubes. These nanotubes were synthesized with the anodic oxidation method and exhibited high-photocatalytic activity for the degradation of 2,3-dichlorophenol in an aqueous solution. Sreekantan et al. [132] prepared anatase-rutile $\mathrm{TiO}_{2}$ nanotubes using the titanium foil anodization method in an electrochemical bath of $1 \mathrm{~mol} / \mathrm{L}$ glycerol with $0.5 \mathrm{wt} \% \mathrm{NH}_{4} \mathrm{~F}$ at a $\mathrm{pH}$ of 6 . Furthermore, it was shown that the anodization voltage could influence the morphology of the anodized and well-aligned growing titanium with pit-like oxide. Ren et al. [133] reported a one-step electrochemical oxidation method which only required a few minutes to prepare mixed-phase $\mathrm{TiO}_{2}$ porous films with oriented rutile. In the synthetic process, the additive amount of $\mathrm{HCl}$ or $\mathrm{HF}$ in the electrolyte could regulate the orientation as well as the rutile nanocrystallites with a large specific surface area. The obtained tailor-oriented $\mathrm{TiO}_{2}$ porous films could produce an enlarged photocurrent based on the treatment of HF which was used as an additive compared to the photocurrent from randomly oriented $\mathrm{TiO}_{2}$ films. Additionally, the synergistic effects of orientation led to a film arrangement with increased exposure of the rutile (101) facets, while the F impurity of the surface showed improved photocatalytic and photoelectrochemical performances. Lv et al. [180] fabricated an $\alpha-\beta$ phase junction in $\mathrm{Bi}_{4} \mathrm{~V}_{2} \mathrm{O}_{11}$ nanofibers based on the electrospinning retardation effect (electrospinning with subsequent calcination), which could transform the $\alpha-\mathrm{Bi}_{4} \mathrm{~V}_{2} \mathrm{O}_{11}$ in $\beta-\mathrm{Bi}_{4} \mathrm{~V}_{2} \mathrm{O}_{11}$ and construct an $\alpha-\beta \mathrm{Bi}_{4} \mathrm{~V}_{2} \mathrm{O}_{11}$ phase junction with a well-defined type-II band alignment, as shown in Fig. 13. The $\alpha-\beta$ phase junction on the $\mathrm{Bi}_{4} \mathrm{~V}_{2} \mathrm{O}_{11}$ nanofibers achieved an outstanding photocatalytic activity used in the removal of $\mathrm{Cr}(\mathrm{VI})$ and MB with the concurrent use of nitrogen fixation.

Several other studies focused on the phases that are naturally induced by extra pressure, induced phase transitions, wire explosion processes, or UV or pulse laser irradiations, in materials such as $\mathrm{Nb}$-doped $\mathrm{TiO}_{2}$ [140] and $\mathrm{RbPbCl}_{3}$ [141]. Lu et al. [140] reported enhanced electron transport in Nb-doped $\mathrm{TiO}_{2}$ nanoparticles based on pressure-induced phase transitions. The electron transport in semiconductors was related to the packing factor of the pressure-induced conductivity evolution. Huang et al. [141] also studied the generation of new pressure-induced phase transitions and their photocatalytic properties in $\mathrm{RbPbCl}_{3}$ using calculations based on fundamental principles. Accordingly, they predicted four new phases, in-
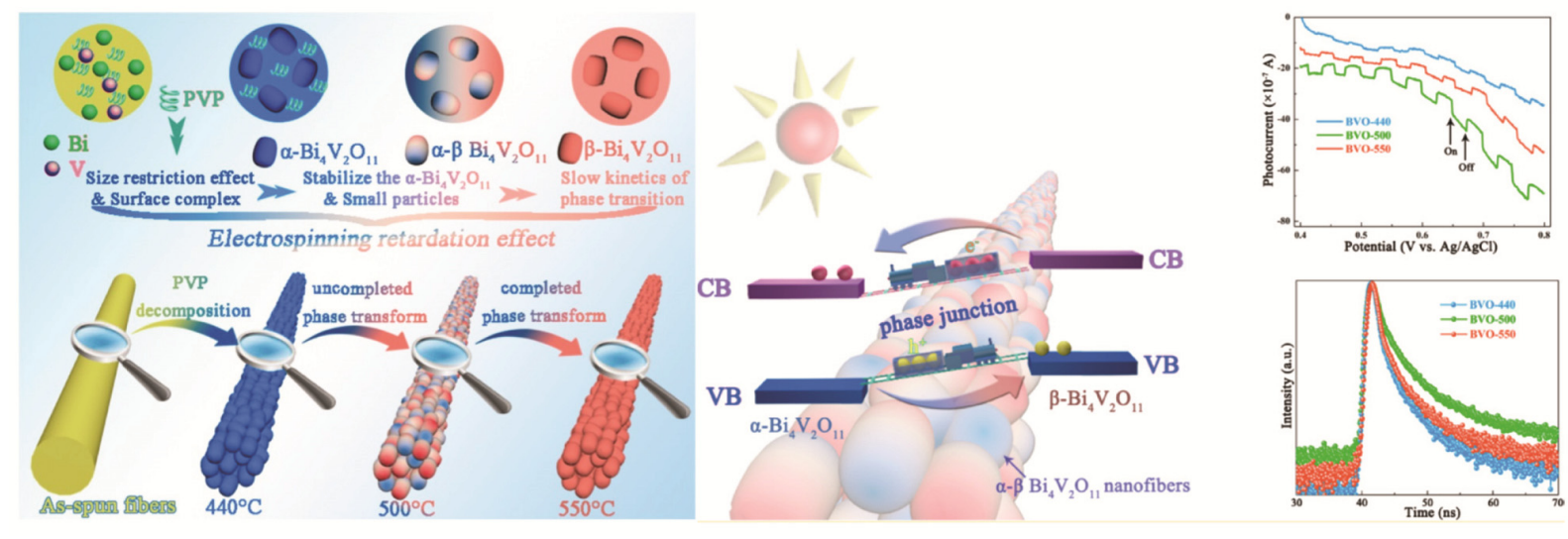

Fig. 13. Formation process and fast separation and transfer of photogenerated carriers on the $\alpha-\beta$ phase junction structure of the $B i_{4} V_{2} \mathrm{O}_{11}$ nanofibers. Reprinted with permission from Ref. [180]. Copyright 2018 ACS. 
cluding $\mathrm{P} 4 / \mathrm{mmm}, \mathrm{C} 2 \mathrm{~mm}, \mathrm{I} 4 \mathrm{~mm}$, and $\mathrm{Cm}$, for $\mathrm{RbPbCl}_{3}$, whereby the electronic structural properties could be modulated by pressure at specific phases. Accordingly, the same authors showed that the $C 2 \mathrm{~mm}, 14 \mathrm{~mm}$, and $\mathrm{Cm}$ phases were promising candidates in photocatalytic water splitting.

Based on the wire explosion process, Ranjan et al. [181] synthesized mixed phases for $\mathrm{TiO}_{2}$ nanoparticles of anatase and rutile in an oxygen atmosphere at a specific pressure. The phase and morphology of $\mathrm{TiO}_{2}$ nanoparticles were governed by the ratio of the stored quantity in the capacitor and the sublimation quantity of the wire. Additionally, the increase of the ratio and the decrease of the oxygen pressure could promote the enhancement of the rutile content. At the two extreme concentration conditions of 300 and $400 \mathrm{mg} / \mathrm{L}$, it exhibited an excellent performance in the photocatalytic removal of methylene blue.

In addition, Zhang et al. [128] reported a UV/ozone-assisted method to prepare mesoporous $\mathrm{TiO}_{2}$ with controlled phase composition at temperatures as low as $100{ }^{\circ} \mathrm{C}$. The exposure time can potentially adjust and control the mixture of the crystalline mesoporous anatase and rutile phases. Choi et al. [129] introduced a facile crystalline phase control method of electrospinning and pulse laser irradiation in liquid to prepare the mixed anatase and rutile phases of $\mathrm{TiO}_{2}$ nanofibers to achieve enhanced photochemical responses and photocatalytic activities in the decomposition of methylene blue. Similarly, Russo et al. [182] studied the phase transformation of $\mathrm{TiO}_{2}$ nanoparticles governed by the femtosecond laser ablation of P25 in aqueous solutions and the deposition on FTO conductive substrates. It was then found that the prolongation of the ablation time of the $\mathrm{TiO}_{2}$ dispersion could widen the bandgap. In other words, it is highly desirable to develop a new, low-cost and effective preparation method for the advancement of phase junctions.

\section{Applications of heterophase/homophase junction photocatalysts}

\subsection{Photocatalytic $\mathrm{H}_{2}$ evolution}

Photocatalytic splitting of water is used to produce hydrogen and is considered as one of the most challenging reactions for the preparation of fuel by solar energy. As the understand- ing of the mechanisms of operation of semiconductor photocatalysts and co-catalysts continues to improve, research progress will continue to be accomplished in the field of photocatalysis. $\mathrm{Li}$ et al. [183] prepared a composite $\mathrm{Sr}_{2} \mathrm{TiO}_{4} / \mathrm{SrTiO}_{3}(\mathrm{La}, \mathrm{Cr})$ heterojunction photocatalyst using a simple, in situ, polymerized complex method. Well defined heterojunctions were formed by matching the lattice fringes of $\mathrm{SrTiO}_{3}(\mathrm{La}, \mathrm{Cr})$ and $\mathrm{Sr}_{2} \mathrm{TiO}_{4}(\mathrm{La}, \mathrm{Cr})$ based on microscopic observations. The absorption spectroscopy and Mott-Schottky plots revealed the band structure of the composite $\mathrm{Sr}_{2} \mathrm{TiO}_{4} / \mathrm{SrTiO}_{3}(\mathrm{La}, \mathrm{Cr})$, and the facts that the photogenerated electrons migrated from $\mathrm{SrTiO}_{3}(\mathrm{La}, \mathrm{Cr})$ to $\mathrm{Sr}_{2} \mathrm{TiO}_{4}(\mathrm{La}, \mathrm{Cr})$ and holes tended to move from $\mathrm{Sr}_{2} \mathrm{TiO}_{4}(\mathrm{La}, \mathrm{Cr})$ to $\mathrm{SrTiO}_{3}(\mathrm{La}, \mathrm{Cr})$ driven by a minor potential difference. These findings indicated the superior photocatalytic activity of photocatalytic $\mathrm{H}_{2}$ production (Fig. 14). A time-resolved FT-IR spectroscopic study confirmed the long-lived electrons and the facilitated charge transfer and separation. Li et al. [184] studied the integration of the nanorod photocatalyst with the hexagonal@cubic CdS core@ shell for highly active production of $\mathrm{H}_{2}$ with unprecedented stability by taking into consideration advantages of core-shell structures in reference to the surface passivation. This shortened the electron diffusion length, increased light absorption, and enhanced the tunneling of charge carriers. The entire process was based on a highly effective, low-cost strategy of the one-pot hydrothermal method, i.e., the direct treatment of cadmium nitrate and thiourea precursor solution at a specific temperature with a variable $\mathrm{Cd} / \mathrm{S}$ precursor molar ratio and reaction time (Fig. 15).

Liu et al. [185] also prepared $\mathrm{CuO}_{x} / \mathrm{TiO}_{2}$ photocatalysts which employed $\mathrm{TiO}_{2}$ with different phase structures, and $\mathrm{CuO}_{x} / \mathrm{P} 25$ with the largest population of $\mathrm{Cu}_{2} \mathrm{O}$-anatase $\mathrm{TiO}_{2}$ heterojunction. These compounds exhibited the highest photocatalytic production of $\mathrm{H}_{2}$. Similarly, Devaraji et al. [186] also synthesized two-dimensional mixed phase leaf- $\mathrm{Ti}_{1-\mathrm{x}} \mathrm{Cu}_{\mathrm{x}} \mathrm{O}_{2}$ sheets. The synthesis was based on a natural leaf template, and the incorporation of $\mathrm{Cu}$ ions $(1 \mathrm{wt} \%)$ into the leaf- $\mathrm{TiO}_{2}$ lattice using a deposition-precipitation method, and was followed by a calcination process. Two-dimensional mixed-phase leaf- $\mathrm{Ti}_{1-\mathrm{x}} \mathrm{Cu}_{\mathrm{x}} \mathrm{O}_{2}$ sheet calcination at $750{ }^{\circ} \mathrm{C}$ led to the highest hydrogen yield. This was mainly attributed to surface-phase junctions, disordering mesoporosity, 2D sheet morphology, and
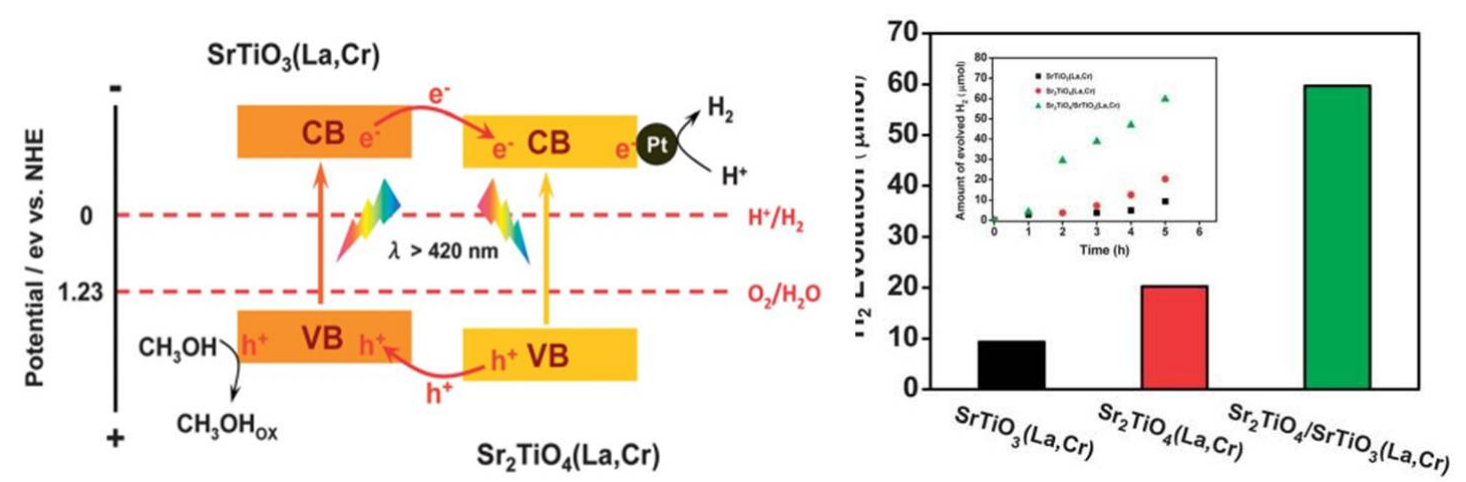

Fig. 14. Schematic band structure and photocatalytic $\mathrm{H}_{2}$ production activities of La and $\mathrm{Cr}$ codoped $\mathrm{Sr}_{2} \mathrm{TiO}_{4} / \mathrm{SrTiO}_{3}$ and its mechanism for $\mathrm{H}_{2}$ production in the presence of visible light irradiation. Reprinted with permission from Ref. [183]. Copyright 2013 RSC. 

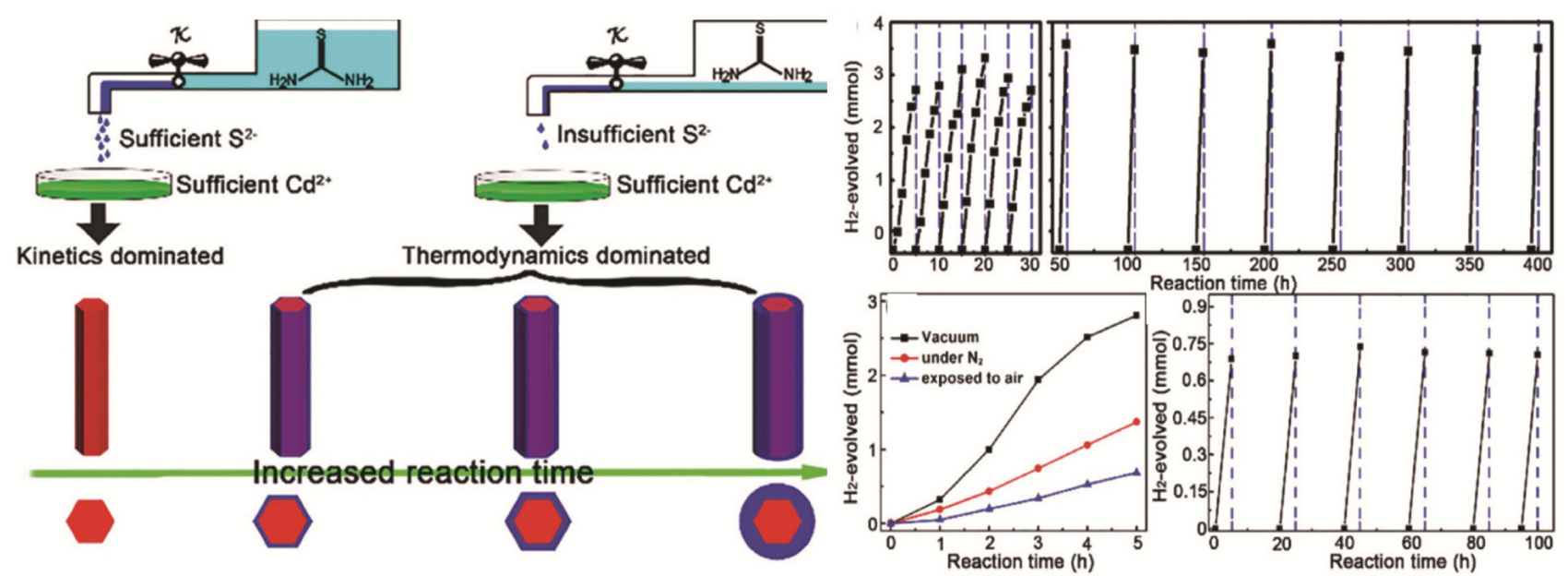

Fig. 15. Formation process and the photocatalytic $\mathrm{H}_{2}$ production activity at different conditions pertaining to the nanorod photocatalyst with the hexagonal@cubic CdS core@ shell. Reprinted with permission from Ref. [184]. Copyright 2016 Wiley.

fast charge carriers. Xu et al. [187] constructed a bi-phasic (anatase/rutile) nanocomposite $\mathrm{TiO}_{2}$ nanofiber photocatalyst with a direct $\mathrm{Z}$ scheme which attained an enhanced photocatalytic $\mathrm{H}_{2}$ production activity. A novel anatase/rutile $\mathrm{TiO}_{2}$ photoelectrode with hydrogenated heterophase interface structures was also found, and was synthesized by the hydrothermal synthesis-hydrogenation-branching growth method [188]. The superior photoelectrochemical (PEC) performance was attributed to the matching energy levels between anatase-branches and the hydrogenated rutile-nanorod, and to the new energy levels of oxygen vacancy and $\mathrm{Ti}-\mathrm{OH}$. Qiu et al. [189] constructed $\mathrm{TiO}_{2}$ hierarchical architecture assembled by nanowires with anatase $/ \mathrm{TiO}_{2}$ (B) phase junctions using a hydrothermal process which was followed by calcination. The optimum calcination treatment at $450{ }^{\circ} \mathrm{C}$ yielded the best photocatalytic hydrogen production activity. Wang et al. [80] constructed the isotype $\mathrm{C}_{3} \mathrm{~N}_{4}$ /sulfur-mediated $\mathrm{C}_{3} \mathrm{~N}_{4}$ heterojunctions of polymeric carbon nitride between two different crystal phases of a single substance (known as crystal-phase heterojunctions) by combining bulk $\mathrm{C}_{3} \mathrm{~N}_{4}$ and the molecularly engineered heptazine tectons in a sulfur medium (sulfur-mediated $\mathrm{C}_{3} \mathrm{~N}_{4}$ can adjust its packing structure and electronic band structure). As shown in Fig. 16, such polymeric isotype heterojunctions show significant enhancements in the activities and durabilities of the $\mathrm{H}_{2}$ evolution reactions. This was attributed to the promoted exciton dissociation and charge separation from the band offsets.

\subsection{Photocatalytic $\mathrm{CO}_{2}$ reduction}

The photocatalytic reduction of $\mathrm{CO}_{2}$ is the conversion of the $\mathrm{C}=\mathrm{O}$ double bonds from linear $\mathrm{CO}_{2}$ molecules to $\mathrm{C}-\mathrm{O}$ single bonds through renewable solar energy, and the use of new catalysts, thereby producing methane, methanol, or olefin, and other products. This can create new chemical supplies to replace the current dependence on oil, coal, and natural gas, and provide an economical and environmentally friendly $\mathrm{CO}_{2}$ utilization process. For example, small metal particle-coated p-Si electrodes $(\mathrm{Cu}, \mathrm{Ag}$, or $\mathrm{Au}$ ) were prepared for the photoelectrochemical reduction of $\mathrm{CO}_{2}$ [190]. These particles had high photovoltages of ca. $0.5 \mathrm{~V}$ and were used as effective electrodes for
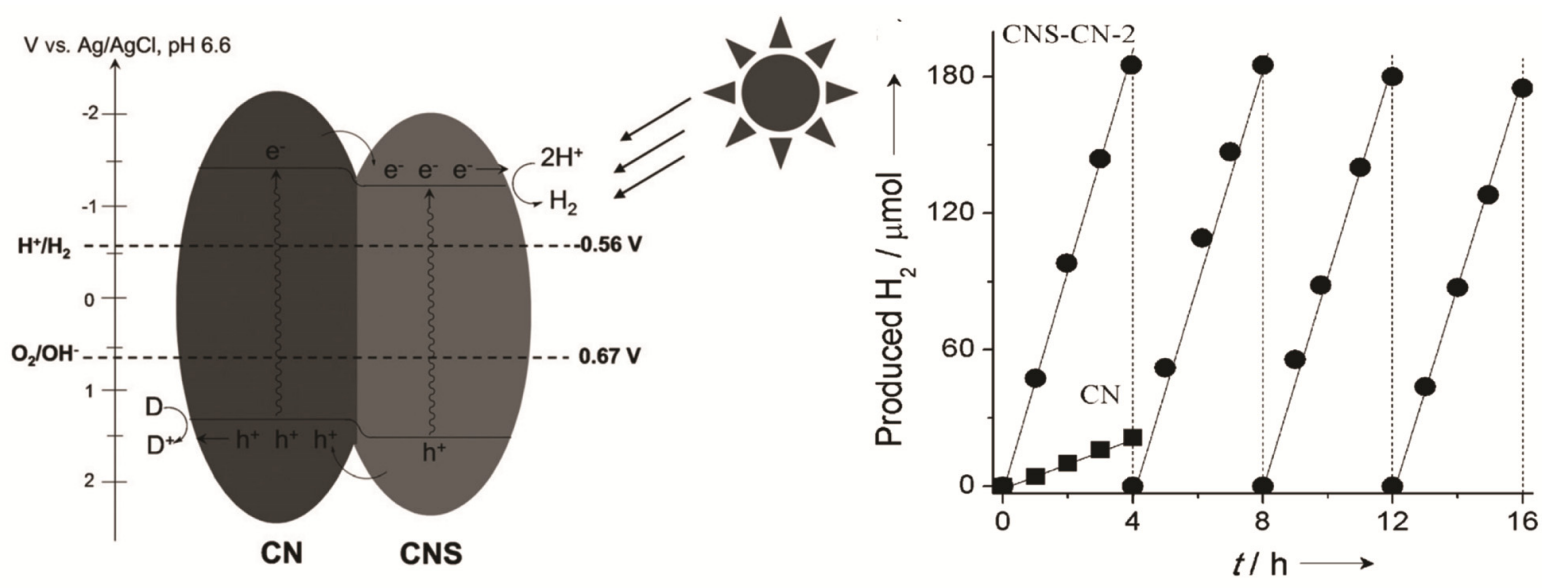

Fig. 16. Organic heterojunction and stability test of the evolution of $\mathrm{H}_{2}$ between $\mathrm{C}_{3} \mathrm{~N}_{4}$ /sulfur-mediated $\mathrm{C}_{3} \mathrm{~N}_{4}$ photocatalysts in the presence of visible-light irradiation. Reprinted with permission from Ref. [80]. Copyright 2012 Wiley. 


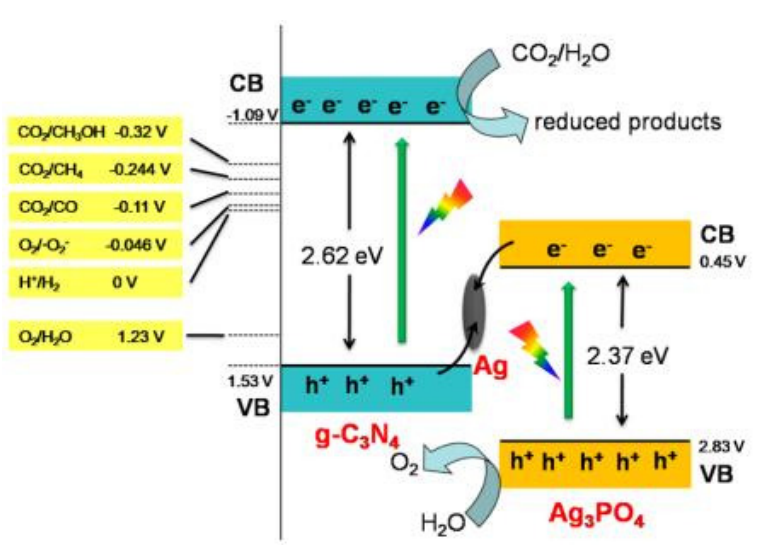

Fig. 17. Photocatalytic mechanism of the $\mathrm{Ag}_{3} \mathrm{PO}_{4} / g-\mathrm{C}_{3} \mathrm{~N}_{4}$. Reprinted with permission from Ref. [86]. Copyright 2015 ACS.

the photoelectrochemical reduction of $\mathrm{CO}_{2}$. He et al. [86] prepared $\mathrm{Ag}_{3} \mathrm{PO}_{4} / \mathrm{Ag} / \mathrm{g}-\mathrm{C}_{3} \mathrm{~N}_{4}$ in situ using g- $\mathrm{C}_{3} \mathrm{~N}_{4}, \mathrm{AgNO}_{3}$, and $\mathrm{Na}_{2} \mathrm{HPO}_{4}$ as raw materials. The photogenerated electrons of $\mathrm{Ag}_{3} \mathrm{PO}_{4}$ and photogenerated holes of $\mathrm{g}-\mathrm{C}_{3} \mathrm{~N}_{4}$ could transfer to $\mathrm{Ag}$ for the recombination (Fig. 17). In this way, the photogenerated electrons could catalyze the reduction of $\mathrm{CO}_{2}$ at the high position of the g- $\mathrm{C}_{3} \mathrm{~N}_{4}$ conduction band, and result in higher activities. The rate of preparation of $\mathrm{C}_{x} \mathrm{H}_{y} \mathrm{O}_{z}$ was as high as 57.5 $\mu \mathrm{mol} \mathrm{h}-1 \mathrm{~g}^{-1}$, and was 6.1 and 10.4 times higher than $\mathrm{g}-\mathrm{C}_{3} \mathrm{~N}_{4}$ and P25, respectively.

Wang et al. [191] designed hierarchical $\operatorname{In}_{2} \mathrm{~S}_{3}-\mathrm{CdIn}_{2} \mathrm{~S}_{4}$ heterostructured nanotubes based on a novel self-template strategy, including sequential anion- and cation-exchange reactions (Fig. 18a). These nanotubes can be efficient and stable photocatalysts for visible light and $\mathrm{CO}_{2}$ reduction owing to the separation and migration of the photoinduced charge carriers, the adsorption and concentration of $\mathrm{CO}_{2}$ molecules, and the abundant number of active sites for surface redox reactions in the hierarchical heterostructured nanotubes. Similarly, the same authors [192] also constructed the sandwich-like $\mathrm{ZnIn}_{2} \mathrm{~S}_{4}-\mathrm{In}_{2} \mathrm{O}_{3}$ hierarchical tubular heterostructures based on (a) the thermal annealing treatment of the in-MIL-68 prism precursor, and (b) the subsequent hydrothermal reaction on the surfaces of the as-derived $\mathrm{In}_{2} \mathrm{O}_{3}$ tubes (Fig. 18b) (growing $\mathrm{ZnIn}_{2} \mathrm{~S}_{4}$ nanosheets on both the inner and outer surfaces of the $\mathrm{In}_{2} \mathrm{O}_{3}$ microtubes) where the optimized $\mathrm{ZnIn}_{2} \mathrm{~S}_{4}-\mathrm{In}_{2} \mathrm{O}_{3}$ exhibited an outstanding performance for $\mathrm{CO}_{2}$ reduction $\left(3075 \mu \mathrm{mol} \mathrm{h} \mathrm{h}^{-1} \mathrm{~g}^{-1}\right)$ and in- creased stability.

\subsection{Photocatalytic degradation}

Hou et al. [193] constructed bismuth oxychloride microflower/nanosheet homojunctions via a solvent-free route for the first time with the controlled reaction temperature owing to some microflowers merging into large nanosheets at $T>120$ ${ }^{\circ} \mathrm{C}$ (Fig. 19). The increased photoactivity of the homojunction sample was attributed to the considerable differences in sizes and the exposed facets between the microflowers and the nanosheets. This allowed the determination of the increased specific surface area and the differences in their energy band levels. Furthermore, Hao et al. [194] fabricated an n-n type bismuth oxychloride ( $\left.\mathrm{BiOCl} / \mathrm{Bi}_{12} \mathrm{O}_{17} \mathrm{Cl}_{2}\right)$ homogeneous phase junction by facilely manipulating the basicity in a one-pot hydrothermal process. The $\mathrm{BiOCl} / \mathrm{Bi}_{12} \mathrm{O}_{17} \mathrm{Cl}_{2}$ phase junctions showed a much higher photocatalytic activity than the single $\mathrm{BiOCl}$ and $\mathrm{Bi}_{12} \mathrm{O}_{17} \mathrm{Cl}_{2}$ toward the degradation of industrial contaminants in the presence of simulated solar light that was attributed to the efficient separation and transfer of photo-induced carriers because of the junction interface between $\mathrm{BiOCl}$ and $\mathrm{Bi}_{12} \mathrm{O}_{17} \mathrm{Cl}_{2}$.

Kondamareddy et al. [195] synthesized $\mathrm{TiO}_{2}$-anatase/rutile heterojunctions by incorporating tungsten $\left(\mathrm{W}^{6+}\right)$ ions into the lattice of pure anatase $\mathrm{TiO}_{2}$ nanoparticles with ultra-trace concentrations (ppm) using a simple one-step hydrothermal method. The enhancement of the photocatalytic activity under visible light irradiation for the degradation of rhodamine B was assigned to the impurity energy levels of the $\mathrm{W}^{6+}$ ions, oxygen vacancies, and the anatase-rutile heterojunction. Gao et al. [196] also investigated the effects of the $\mathrm{C}$ and $\mathrm{Y}$ doping and annealing temperatures on the structural and optical properties and photocatalytic activity of mixed phase $\mathrm{TiO}_{2}$. It was found that $\mathrm{C}$ and $\mathrm{Y}$ doping can broaden the absorption spectrum of $\mathrm{TiO}_{2}$, increase the specific surface area, and enhance the photocatalytic activity. Makal et al. [197] studied (a) $\mathrm{TiO}_{2}$ nanowires with different phases using the hydrothermal technique, e.g., $\mathrm{TiO}_{2}-\mathrm{B}$, anatase, and rutile, and (b) the subsequent thermal annealing process in vacuum at different temperatures, and investigated their photocatalytic performance. The $\mathrm{TiO}_{2}$ - $\mathrm{B} /$ anatase heterostructured nanowires by partial phase transformation at $700{ }^{\circ} \mathrm{C}$ showed enhanced photocatalytic ca-
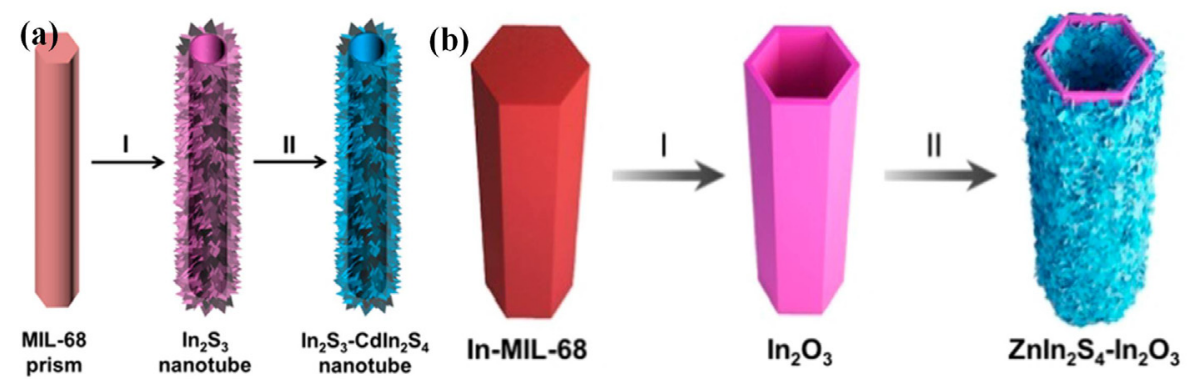

Fig. 18. Schematic illustration of the synthetic process of hierarchical (a) $\operatorname{In}_{2} \mathrm{~S}_{3}-\mathrm{Cd} \operatorname{In}_{2} \mathrm{~S}_{4}$ and (b) $\mathrm{ZnIn}_{2} \mathrm{~S}_{4}-\mathrm{In}_{2} \mathrm{O}_{3}$ heterostructures. Reprinted with permission from Refs. [191,192]. Copyright 2017, 2018 ACS. 

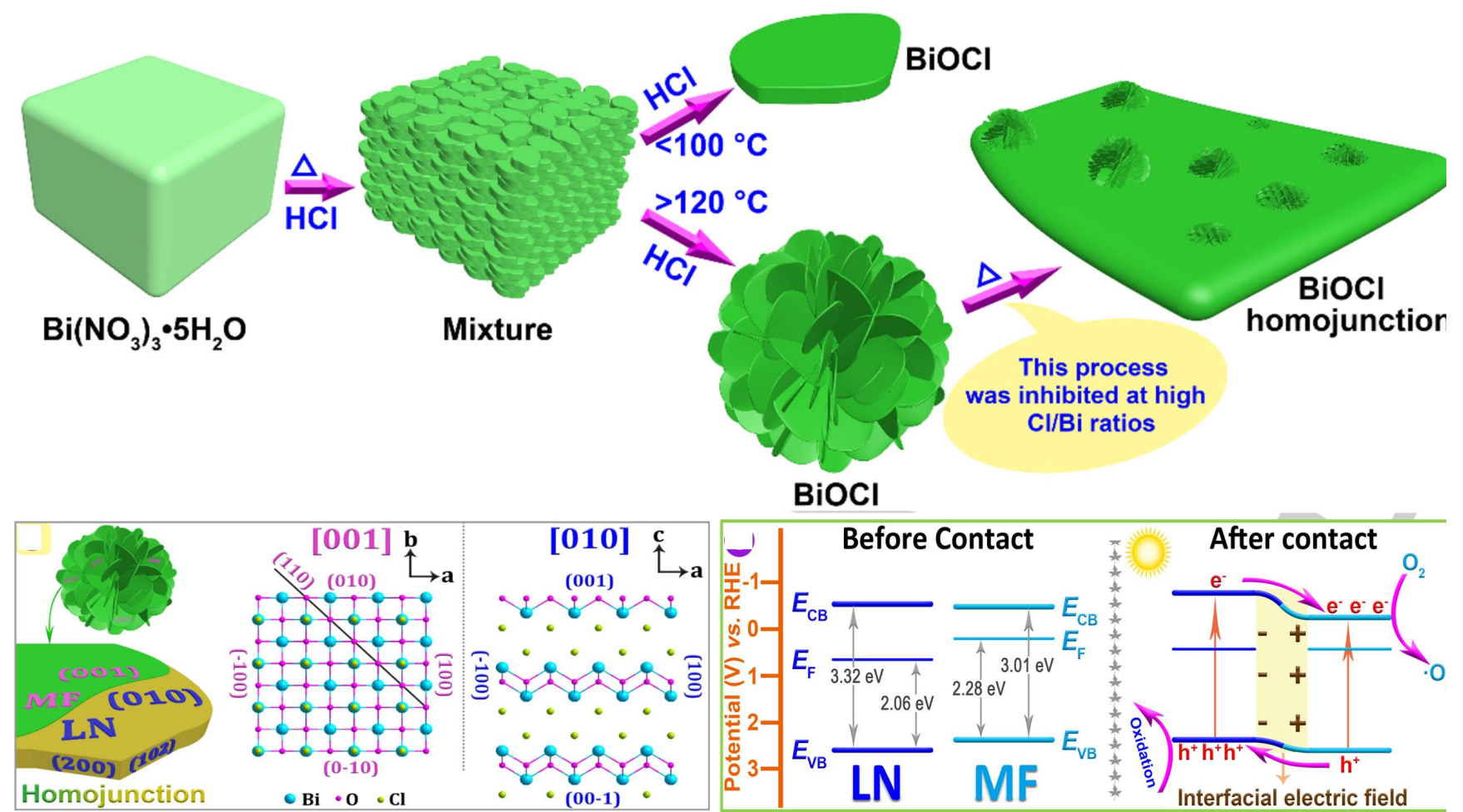

Fig. 19. Formation and growth process, energy band levels, and photogenerated charge carrier transfer pathways of BiOCl microflower/nanosheet homojunctions. Reprinted with permission from Ref. [193]. Copyright 2018 Wiley.

pacity because of their broad optical band gaps.

Jo et al. [198] fabricated a unique Janus $\mathrm{Ag}_{2} \mathrm{O} / \mathrm{Ag}_{2} \mathrm{CO}_{3}$ heterojunction photocatalyst with improved photocatalytic properties using in situ phase transformation, and Zhao et al. [199] reported $\mathrm{Ag}_{2} \mathrm{O} / \mathrm{Ag}_{2} \mathrm{CO}_{3} 3 \mathrm{D}$ hollow flower-like hierarchical microspheres, which exhibited improved photocatalytic performance and stability compared to those of bare $\mathrm{Ag}_{2} \mathrm{CO}_{3}$. Wang et al. [200] fabricated $\mathrm{TiO}_{2}$ (B)/anatase heterophase junctions in nanowires via a surface-preferred phase transformation process, i.e., a three-step synthesis method, including hydrothermal treatment, $\mathrm{H}^{+}$exchange, and annealing. The optimized structure with $24 \% \mathrm{TiO}_{2}$ (B) in the bulk and $100 \%$ anatase on the surface led to an enhanced photocatalytic activity (Fig. 20).
Samsudin et al. [201] fabricated bluish-gray hydrogenated $\mathrm{TiO}_{2}$ by hydrogenating it at constant temperature and pressure with controlled hydrogenation duration. They demonstrated that the photocatalytic activity was attributed to the increased oxygen vacancies and $\mathrm{Ti}^{3+}$ for solar light absorption, while the extended hydrogenation duration caused decreases in the activity owing to the excessive catalyst growth and loss in the total surface area. Li et al. [202] studied the charge transfer at an anatase/rutile $\mathrm{TiO}_{2}$ phase junction using time-resolved photoluminescence spectroscopy, and found that the charge separation at the anatase/rutile phase junction reduced the microsecond time scale photoluminescence decay rate for the charge carriers because of the slower electron-hole recombination (a)

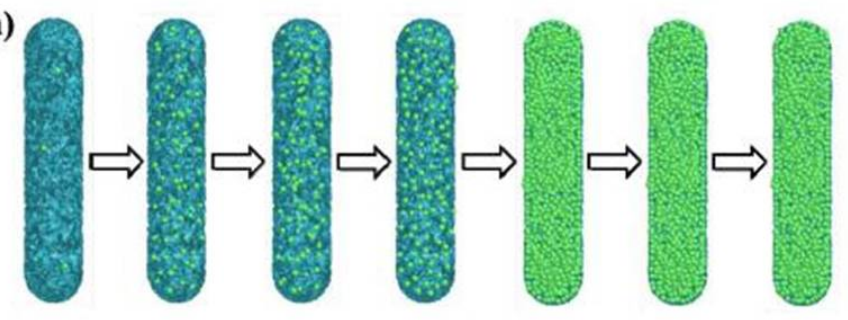

(b)

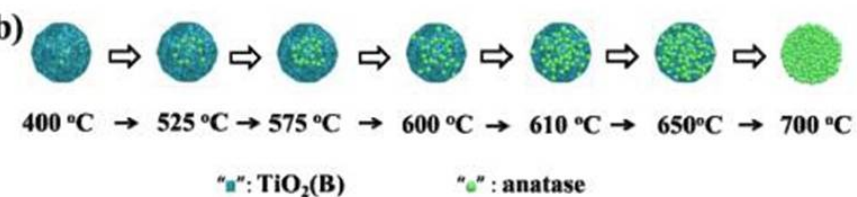

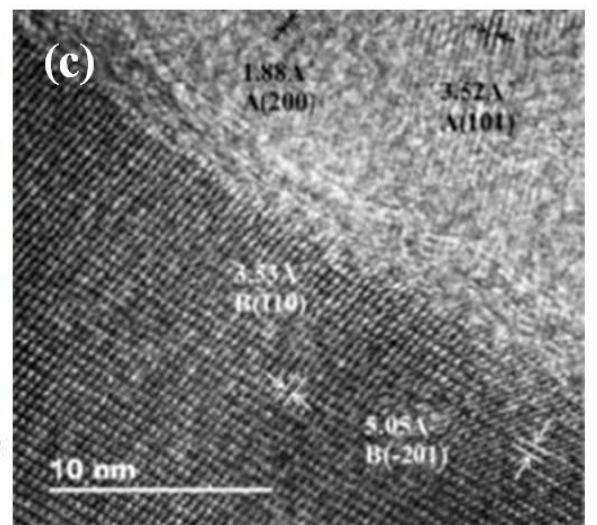

Fig. 20. Formation and growth process of the phase transformation (a) on the surface, (b) in the bulk, and (c) at the surface-preferred phase junction at $600^{\circ} \mathrm{C}$. Reprinted with permission from Ref. [200]. Copyright 2018 Elsevier. 
(Fig. 21). Moro et al. [203] studied the mesoporous and nanocrystalline titanium dioxide by a possible synergism between $\mathrm{TiO}_{2}$ and carbon nanotubes under hydrothermal conditions. Based on this study, they showed that the addition of a small amount of MWCNTs further increased the photoactivity of the nanocrystalline titania for the degradation of 4-nitrophenol.

Because of the different band structures of g- $\mathrm{C}_{3} \mathrm{~N}_{4}$ prepared separately from urea and thiourea using the same thermal conditions, Dong et al. [204] prepared a novel layered g- $\mathrm{C}_{3} \mathrm{~N}_{4} / \mathrm{g}-\mathrm{C}_{3} \mathrm{~N}_{4}$ metal-free isotype heterojunction in situ with molecular composite precursors, which exhibited significantly enhanced photocatalytic activity for visible light for the remov-

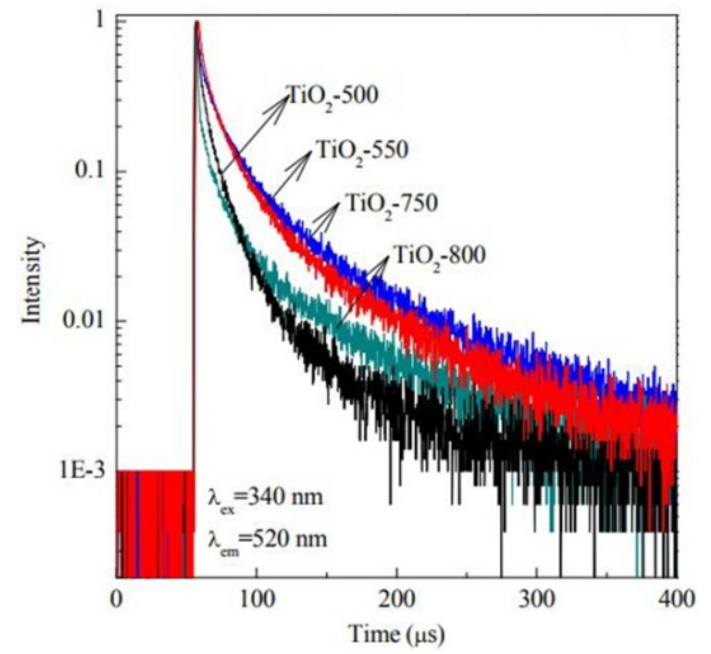

al of NO from air. This was directly ascribed to an efficient charge separation and transfer across the heterojunction interface and to the prolonged lifetime of charge carriers, as indicated in Fig. 22. Meanwhile, Liu et al. [205] studied an amorphous/crystalline g- $\mathrm{C}_{3} \mathrm{~N}_{4}$ homojunction with a matched energy level structure via a two-step polymerization of melemon at the surface of crystalline g- $\mathrm{C}_{3} \mathrm{~N}_{4}$ (as seeds). They also optimized the ratio of crystalline $\mathrm{g}-\mathrm{C}_{3} \mathrm{~N}_{4}$ in the homojunction that resulted in a superior photocatalytic performance for the degradation of organic pollutants under visible light irradiation. The synthetic process and photocatalytic degradation of $\mathrm{RhB}$ of composites are shown in Fig. 23.

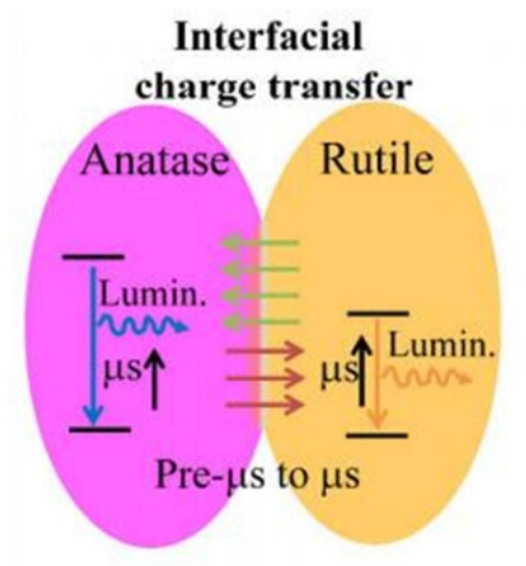

Anatase:Rutile Phase Junction

Fig. 21. PL decays of $\mathrm{TiO}_{2}$ samples with different phase compositions at the excitation source of $340 \mathrm{~nm}$, and charge transfer and recombination at anatase/rutile phase junction. Reprinted with permission from Ref. [202]. Copyright 2016 Elsevier.
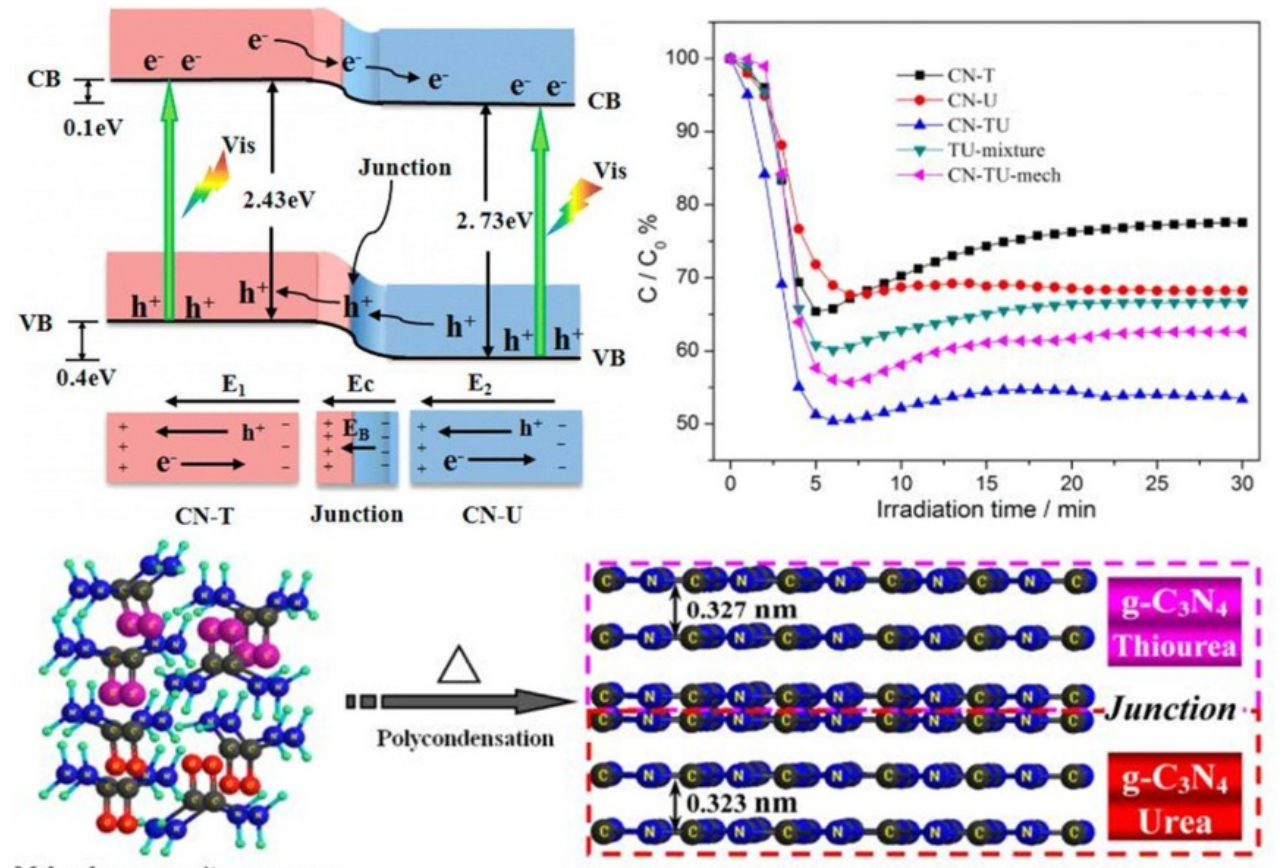

Molecular composite precursor

Fig. 22. Charge transfer, visible-light photocatalytic performance, and in situ formation process of the $\mathrm{CN}-\mathrm{T} / \mathrm{CN}-\mathrm{U}$ isotype heterojunction. Reprinted with permission from Ref. [204]. Copyright 2013 ACS. 

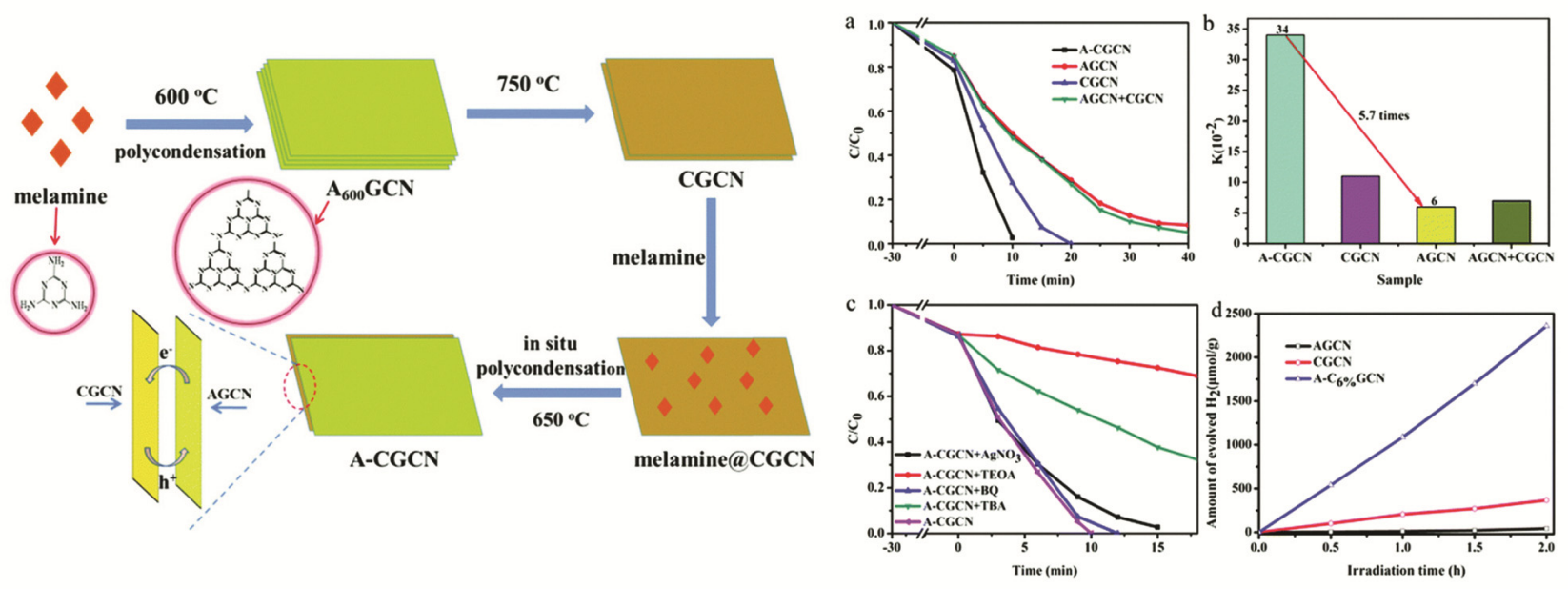

Fig. 23. Preparation process and photocatalytic degradation of RhB of amorphous/crystalline g- $\mathrm{C}_{3} \mathrm{~N}_{4}$ composites. Reprinted with permission from Ref. [205]. Copyright 2018 RSC.

\section{Conclusions and perspectives}

Highly efficient photocatalysts are required to maximize the solar spectrum usage that ultimately leads to an effective separation of photo-generated electron-hole pairs. The separated electron-hole pairs can be transferred to the surface of the catalysts and react with substrates. Nanocrystalline heterojunction photocatalytic materials, including semiconductor/semiconductor, semiconductor/metal, semiconductor/nonmetal, and surface heterojunctions, have successfully achieved the effective separation and long-term stability of carriers.

With respect to Table 2, we discussed the general strategies and recent progress with the use of efficient techniques for the construction of phase junctions for the development of highly efficient and stable photocatalysts, including: (1) the addition of a suitable amount of anions or positive ions (such as $\mathrm{Cl}^{-}, \mathrm{F}^{-}$, $\mathrm{PO}_{4}{ }^{3-}, \mathrm{SO}_{4}{ }^{2-}$, and $\mathrm{Mo}^{6+}$ ) to regulate the phase transition on undoped semiconductor photocatalysts, (2) the implementation of oxide regulation in the phase transition process of the photocatalysts to improve the photocatalytic activity of the phase junction, (3) the induction of phase junctions with the soft chemical route to achieve exceptional and synergistic photo-

Table 2 Comparison of the typical heterojunctions based on an externally driven phase transformation.

\begin{tabular}{|c|c|c|c|c|}
\hline Formation technique & Types & Preparation & Improved performance & Proposed reasons \\
\hline $\begin{array}{l}\text { Anionic and cationic } \\
\text { regulations }\end{array}$ & $\begin{array}{c}\mathrm{Mo}^{6+}, \mathrm{Mn}^{2+}, \mathrm{Cl}^{-}, \mathrm{F}^{-}, \mathrm{NO}_{3}{ }^{-}, \mathrm{HCO}_{3}{ }^{-} \\
\mathrm{PO}_{4}{ }^{3-}, \mathrm{SiO}_{3}{ }^{2-}, \text { and } \mathrm{MoO}_{4}{ }^{2-}\end{array}$ & $\begin{array}{l}\text { Regulation of the composi- } \\
\text { tion of anatase-rutile phase } \\
\text { of } \mathrm{TiO}_{2}\end{array}$ & $\begin{array}{l}\text { Higher activities than that of } \\
\text { industrial } \mathrm{P} 25 \text { in the } \\
\text { photocatalytic } \mathrm{H}_{2} \text { production }\end{array}$ & $\begin{array}{c}\text { Effective separation of the } \\
\text { photogenerated electron-hole } \\
\text { pair }\end{array}$ \\
\hline Oxide regulations & $\mathrm{Al}_{2} \mathrm{O}_{3}, \mathrm{Nd}_{2} \mathrm{O}_{3}, \mathrm{SiO}_{2}$ & Anatase-rutile type & $\begin{array}{c}\text { Promotion of the degradation } \\
\text { of RhB }\end{array}$ & $\begin{array}{l}\text { Prevention of the accumulation } \\
\text { of } \mathrm{TiO}_{2} \text { grain growth }\end{array}$ \\
\hline Soft chemical route & $\begin{array}{c}\alpha-/ \gamma-\mathrm{Bi}_{2} \mathrm{O}_{3} \text { homojunction, } \\
\alpha / \beta-\mathrm{Bi}_{2} \mathrm{O}_{3} \text { homojunction, } \\
2 \mathrm{H} / 1 \mathrm{~T}-\mathrm{MoS}_{2} / \mathrm{C}_{3} \mathrm{~N}_{4} \text {, mixed-phase } \\
\mathrm{TiO}_{2}, \mathrm{TiO}_{2}(\mathrm{~B}) / \text { rutile/rookite, } \\
\mathrm{Bi}_{2} \mathrm{O}_{2} \mathrm{CO}_{3} / \mathrm{Bi}_{2} \mathrm{O}_{4}\end{array}$ & $\begin{array}{l}\text { A one-pot hydrothermal } \\
\text { method or a novel } \\
\text { solvothermal } \\
\text { calcination method }\end{array}$ & $\begin{array}{l}\text { Exceptional and synergistic } \\
\text { photocatalytic activity }\end{array}$ & $\begin{array}{c}\text { Enhanced separation of } \\
\text { photogenerated electron and } \\
\text { hole pairs }\end{array}$ \\
\hline Control of calcination & $\begin{array}{c}\mathrm{Ag}_{2} \mathrm{CO}_{3} @ \mathrm{Ag}_{2} \mathrm{O}, \mathrm{BiOI} / \mathrm{Bi}_{5} \mathrm{O}_{7} \mathrm{I} \\
\mathrm{Bi}_{5} \mathrm{O}_{7} \mathrm{I} / \mathrm{Bi}_{2} \mathrm{O}_{3}, \mathrm{BiOBr} / \mathrm{Bi}_{24} \mathrm{O}_{31} \mathrm{Br} \\
\mathrm{Bi}_{24} \mathrm{O}_{31} \mathrm{Br} / \alpha-\mathrm{Bi}_{2} \mathrm{O}_{3}, \\
\beta-\mathrm{Bi}_{2} \mathrm{O}_{3} / \mathrm{Bi}_{2} \mathrm{O}_{2.33} @ \mathrm{Bi}_{2} \mathrm{O}_{2} \mathrm{CO}_{3}, \\
\mathrm{Zn}_{3}\left(\mathrm{VO}_{4}\right)_{2} / \mathrm{Zn}_{2} \mathrm{~V}_{2} \mathrm{O}_{7} / \mathrm{ZnO}, \\
\mathrm{Sr}_{2} \mathrm{Ta}_{2} \mathrm{O}_{7-\chi} \mathrm{N}_{x} / \mathrm{SrTaO}_{2} \mathrm{~N}, \alpha-\beta \mathrm{Ga}_{2} \mathrm{O}_{3}\end{array}$ & $\begin{array}{l}\text { Control of heating } \\
\text { temperature, time, and } \\
\text { atmosphere }\end{array}$ & $\begin{array}{l}\text { Higher photocatalytic activity } \\
\text { than single primitive sample }\end{array}$ & $\begin{array}{l}\text { Energy level matching and } \\
\text { an internal electric field } \\
\text { accelerate the separation of } \\
\text { photogenerated carriers }\end{array}$ \\
\hline $\begin{array}{l}\text { Self-surface phase } \\
\text { junctions of crystal } \\
\text { plane }\end{array}$ & $\begin{array}{l}(101) \text { and }(001) \text { surfaces of } \mathrm{TiO}_{2} \text {, } \\
(001) \text { facet of cubic } \mathrm{Cu}_{2} \mathrm{O},(010) \\
\text { and (110) crystal facets of } \mathrm{BiVO}_{4}\end{array}$ & $\begin{array}{l}\text { Design of a single crystal } \\
\text { semiconductor }\end{array}$ & $\begin{array}{l}\text { Improved } \mathrm{CO}_{2} \text { reduction and } \\
\mathrm{H}_{2} \text { production rate }\end{array}$ & $\begin{array}{c}\text { Spatial separation of } \\
\text { photogenerated electrons and } \\
\text { holes on different crystal facets }\end{array}$ \\
\hline Electro-chemistry & $\alpha-\beta \mathrm{Bi}_{4} \mathrm{~V}_{2} \mathrm{O}_{11}$, mixed-phase $\mathrm{TiO}_{2}$ & $\begin{array}{c}\text { Anodic oxidation or } \\
\text { one-step electrochemical } \\
\text { oxidation }\end{array}$ & $\begin{array}{l}\text { Outstanding photocatalytic } \\
\text { activity in the removal of } \\
\text { Cr(VI) and MB, and nitrogen } \\
\text { fixation }\end{array}$ & $\begin{array}{l}\text { Well-established type-II band } \\
\text { alignment }\end{array}$ \\
\hline Pressure induction & Nb-doped $\mathrm{TiO}_{2}$ & Extra pressure & $\begin{array}{c}\text { Promotion of photocatalytic } \\
\text { water splitting }\end{array}$ & Enhanced electron transport \\
\hline
\end{tabular}


catalytic activity, (4) the control of calcination-induced phase junctions based on the control of the phase transition rate and time, (5) the creation of self-surface phase junctions of the crystal plane to improve the separation and transportation of the electron-hole pairs, (6) the use of other assistant-driven phase junctions, such as pulse laser irradiation, UV/ozone, and electrochemistry methods, for the enhancement of the utilization of sunlight and the improvement of the separation/transportation of the carriers. The efficient techniques in this field associated with phase transitions provided a promising route to the preparation of the phase junctions and to the enhancement of the photocatalytic efficiencies.

The factors that affect the performance of photocatalysts are very complex. Accordingly, the photocatalytic activity was not only influenced by its phase structure, but also by its surface chemical properties. These factors introduced many difficulties in the interpretation of nanocrystalline heterostructures with the use of the traditional solid band theory. Therefore, the research of phase junction photocatalytic materials at the nanometer scale may be focused on the following aspects: (1) development of simple, cheap, large-scale, and pollution-free preparation technologies of phase transitions, to regulate the energy band structure of the nanoscale heterojunction and to improve the matching degree of the energy band; (2) design of a suitable preparation method to construct a novel and efficient heterogeneous structure type according to the properties and the final structure of the related semiconductors; (3) fabrication of nano-heterojunction photocatalytic materials in devices and application to the actual photocatalysis control process. It is necessary to use the effective in situ and transient technologies to study the actual charge transfer of nanocrystalline het- erostructures for the establishment of a suitable theory for nanocrystalline heterostructures.

\section{Acknowledgments}

This work was financially supported by the National Natural Science Foundation of China (21707055, 21567008, 21607064), Program of Qingjiang Excellent Young Talents, Jiangxi University of Science and Technology, Program of 5511 Talents in Scientific and Technological Innovation of Jiangxi Province (20165BCB18014), Academic and Technical Leaders of the Main Disciplines in Jiangxi Province (20172BCB22018), Jiangxi Province Natural Science Foundation (20161BAB203090, 20181BAB213010, 20181BAB203018), Young Science Foundation of Jiangxi Province Education Office (GJJ160671), Open Project Program of the State Key Laboratory of Photocatalysis on Energy and Environment (SKLPEE-KF201712) in Fuzhou University and Doctoral Fund of Jiangxi University of Science and Technology.

\section{References}

[1] A. Kudo, Y. Miseki, Chem. Soc. Rev., 2009, 38, 253-278.

[2] Y. Ma, X. Wang, Y. Jia, X. Chen, H. Han, C. Li, Chem. Rev., 2014, 114, 9987-10043.

[3] Y. Qu, X. Duan, Chem. Soc. Rev., 2013, 42, 2568-2580.

[4] H. Wang, L. Zhang, Z. Chen, J. Hu, S. Li, Z. Wang, J. Liu, X. Wang, Chem. Soc. Rev., 2014, 43, 5234-5244.

[5] M. D. Hernández-Alonso, F. Fresno, S. Suárez, J. M. Coronado, Energy Environ. Sci., 2009, 2, 1231-1257.

[6] G. Liu, C. Sun, L. Cheng, Y. Jin, H. Lu, L. Wang, S. C. Smith, G. Q. Lu, H.

\section{Graphical Abstract}

Chin. J. Catal., 2019, 40: 796-818 doi: S1872-2067(19)63290-0

Review on heterophase/homophase junctions for efficient photocatalysis: The case of phase transition construction

Kai Yang, Xiaoxiao Li, Changlin Yu *, Debin Zeng, Fanyun Chen, Kailian Zhang, Weiya Huang, Hongbing Ji**

Jiangxi University of Science and Technology; Guangdong University of Petrochemical Technology

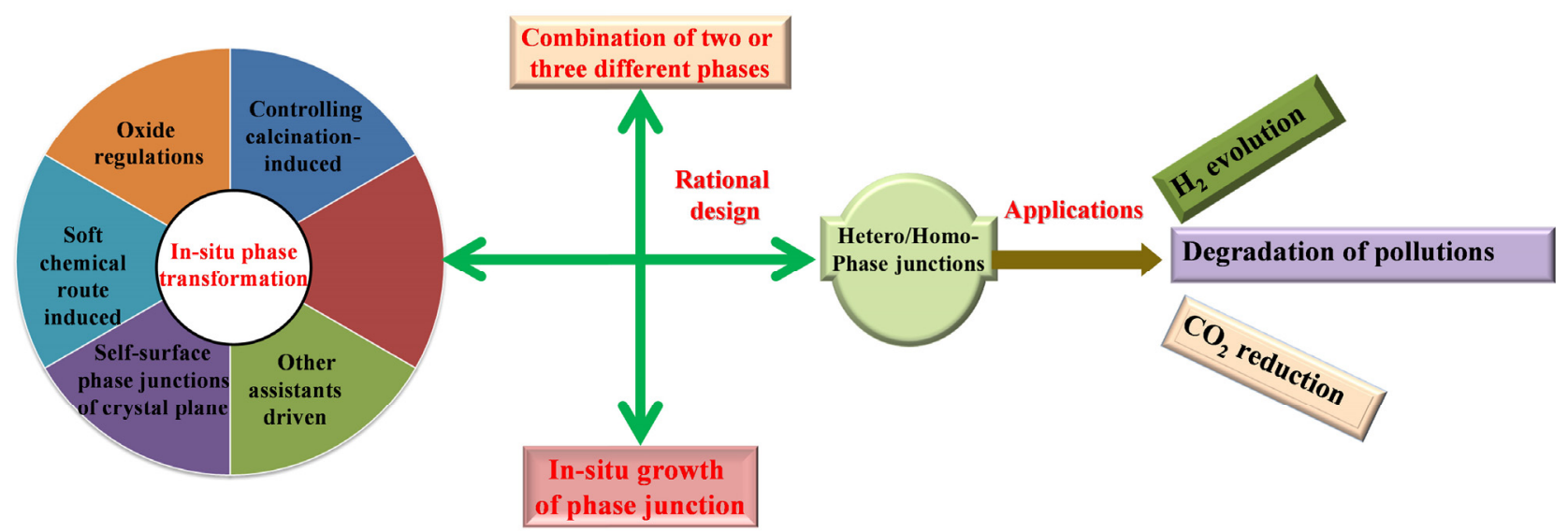

Applications of the low-cost and efficient phase junction pathway for the construction of nanophase junctions in photocatalysis. 
M. Cheng, J. Phys. Chem. C, 2009, 113, 12317-12324.

[7] W. Hu, W. Zhou, K. Zhang, X. Zhang, L. Wang, B. Jiang, G. Tian, D. Zhao, H. Fu, J. Mater. Chem. A, 2016, 4, 7495-7502.

[8] Z. Xing, J. Zhang, J. Cui, J. Yin, T. Zhao, J. Kuang, Z. Xiu, N. Wan, W. Zhou, Appl. Catal. B, 2018, 225, 452-467.

[9] C. Yu, W. Zhou, C. Y. Jimmy, H. Liu, L. Wei, Chin. J. Catal., 2014, 35, 1609-1618.

[10] C. Yu, W. Zhou, H. Liu, Y. Liu, D. D. Dionysiou, Chem. Eng. J., 2016, 287, 117-129.

[11] H. B. He, S. S. Xue, Z. Wu, C. L. Yu, K. Yang, G. M. Peng, W. Q. Zhou, D. H. Li, Chin. J. Catal., 2016, 37, 1841-1850.

[12] L. Y. Ozer, H. Apostoleris, F. Ravaux, S. I. Shylin, F. Mamedov, A. Lindblad, F. O. L. Johansson, M. Chiesa, J. Sa, G. Palmisano, ChemCatChem, 2018, 10, 2949-2954.

[13] F. Y. Li, Q. Gu, Y. Niu, R. Z. Wang, Y. C. Tong, S. Y. Zhu, H. L. Zhang, Z. Z. Zhang, X. X. Wang, Appl. Surf. Sci., 2017, 391, 251-258.

[14] H. J. Yu, H. W. Huang, K. Xu, W. C. Hao, Y. X. Guo, S. B. Wang, X. L. Shen, S. F. Pan, Y. H. Zhang, ACS Sustain. Chem. Eng., 2017, 5, 10499-10508.

[15] H. G. Yu, W. Zhong, X. Huang, P. Wang, J. G. Yu, ACS Sustain. Chem. Eng., 2018, 6, 5513-5523.

[16] F. E. Osterloh, Chem. Mater., 2008, 20, 35-54.

[17] X. Chen, S. Shen, L. Guo, S. S. Mao, Chem. Rev., 2010, 110, 6503-6570.

[18] R. Li, C. Li, Adv. Catal., 2017, 60, 1-57.

[19] W. Hou, W. H. Hung, P. Pavaskar, A. Goeppert, M. Aykol, S. B. Cronin, ACS Catal., 2011, 1, 929-936.

[20] A. Corma, H. Garcia, J. Catal., 2013, 308, 168-175.

[21] V. S. Thoi, N. Kornienko, C. G. Margarit, P. Yang, C. J. Chang, J. Am. Chem. Soc, 2013, 135, 14413-14424.

[22] A. L. Linsebigler, G. Lu, J. T. Yates Jr., Chem. Rev., 1995, 95, 735-758.

[23] Y. Lv, C. Pan, X. Ma, R. Zong, X. Bai, Y. Zhu, Appl. Catal. B, 2013, 138-139, 26-32.

[24] Z. Yi, J. Ye, N. Kikugawa, T. Kako, S. Ouyang, H. S. Williams, H. Yang, J. Cao, W. Luo, Z. Li, Y. Liu, R. L. Withers, Nat. Mater., 2010, 9, 559-564.

[25] H. Dong, G. Chen, J. Sun, C. Li, Y. Yu, D. Chen, Appl. Catal. B, 2013, 134-135, 46-54.

[26] Z. R. Tang, B. Han, C. Han, Y. J. Xu, J. Mater. Chem. A, 2017, 5, 2387-2410.

[27] J. S. Hu, L. L. Ren, Y. G. Guo, H. P. Liang, A. M. Cao, L. J. Wan, C. L. Bai, Angew. Chem. Int. Ed., 2005, 44, 1269-1273.

[28] Z. Hu, L. Yuan, Z. Liu, Z. Shen, J. C. Yu, Angew. Chem. Int. Ed., 2016, $55,9580-9585$.

[29] X. Zhu, T. Zhang, Z. Sun, H. Chen, J. Guan, X. Chen, H. Ji, P. Du, S. Yang, Adv. Mater., 2017, 29, 1605776/1-1605776/7.

[30] G. Liu, P. Niu, L. Yin, H. M. Cheng, J. Am. Chem. Soc, 2012, 134, 9070-9073.

[31] W. J. Ong, L. L. Tan, Y. H. Ng, S. T. Yong, S. P. Chai, Chem. Rev., 2016, $116,7159-7329$.

[32] Q. Xiang, B. Cheng, J. Yu, Angew. Chem. Int. Ed., 2015, 54, 11350-11366.

[33] M. R. Gholipour, C. T. Dinh, F. Béland, T. O. Do, Nanoscale, 2015, 7, 8187-8208.

[34] P. Zhou, J.Yu, M. Jaroniec, Adv. Mater., 2014, 26, 4920-4935.

[35] D. Xu, B. Cheng, W. Wang, C. Jiang, J. Yu, Appl. Catal. B, 2018, 231, 368-380.

[36] S. Meng, X. Ning, T. Zhang, S. F. Chen, X. Fu, Phys. Chem. Chem. Phys., 2015, 17, 11577-11585.

[37] P. Heremans, D. Cheyns, B. P. Rand, Acc. Chem. Res., 2009, 42, 1740-1747.
[38] D. Jiang, L. Chen, J. Zhu, M. Chen, W. Shi, J. Xie, Dalton Trans., 2013, 42, 15726-15734.

[39] W. Sun, S. Meng, S. Zhang, X. Zheng, X. Ye, X. Fu, S. Chen, J. Phys. Chem. C, 2018, 122, 15409-15420.

[40] T. Xiao, Z. Tang, Y. Yang, L. Tang, Y. Zhou, Z. Zou, Appl. Catal. B, 2018, 220, 417-428.

[41] F. Withers, P. O. Del, A. Mishchenko, A. P. Rooney, A. Gholinia, K. Watanabe, T. Taniguchi, S. J. Haigh, A. K. Geim, A. I. Tartakovskii, K. S. Novoselov, Nat. Mater., 2015, 14, 301-306.

[42] X. Wang, F. Xia, Nat. Mater., 2015, 14, 264-265.

[43] W. Chen, Y. Hu, M. W. Ba, Appl. Surf. Sci., 2018, 435, 483-493.

[44] H. D. She, L. S. Li, Y. D. Sun, L. Wang, J. W. Huang, G. Q. Zhu, Q. Z. Wang, Appl. Surf. Sci., 2018, 457, 1167-1173.

[45] V. Madhavi, P. Kondaiah, H. Shaik, G. M. Raoa, Appl. Surf. Sci., 2016, 364, 732-739.

[46] H. Yu, Prog. Chem., 2009, 75, 4653-4656.

[47] H. Zheng, Y. Li, H. Liu, X. Yin, Y. Li, Chem. Soc. Rev., 2011, 40, 4506-4524.

[48] H. Du, Y. N. Liu, C. C. Shen, A. W. Xu, Chin. J. Catal., 2017, 38, 1295-1306.

[49] X. H. Li, M. Antonietti, Chem. Soc. Rev., 2013, 42, 6593-6604.

[50] M. Chen, H. Shen, X. Li, H. F. Liu, Appl. Surf. Sci, 2014, 307, 306-310.

[51] M. Marchelek, E. Grabowska, T. Klimczuk, W. Lisowski, A. Zaleska-Medynska, Appl. Surf. Sci., 2017, 393, 262-275.

[52] D. Y. Fan, R. F. Chong, F. T. Fan, X. L. Wang, C. Li, Z. C. Feng, Chin. J. Catal., 2016, 37, 1257-1262.

[53] S. Wang, J. H. Yun, B. Luo, T. Butburee, P. Peerakiatkhajohn, S. Thaweesak, M. Xiao, L. Wang, J. Mater. Sci. Technol., 2017, 33, $1-22$.

[54] D. A. H. Hanaor, J. Mater. Sci., 2011, 46, 855-874.

[55] L. Wang, W. A. Daoud, Appl. Surf. Sci., 2015, 324, 532-537.

[56] J. Kong, X. Lai, Z. Rui, H. Ji, S. Ji, Chin. J. Catal., 2016, 37, 869-877.

[57] Y. Ma, X. Wang, C. Li. Chin. J. Catal., 2015, 36, 1519-1527.

[58] Y. Sun, W. Wang, L. Zhang, Z. Zhang, Chem. Eng. J., 2012, 211-212, 161-167.

[59] Y. Shi, L. Luo, Y. Zhang, Y. Chen, S. Wang, L. Li, Y, Long, F. Jiang, Ceram. Int., 2017, 43, 7627-7635.

[60] J. Zhu, F. Fan, R. Chen, H. An, Z. Feng, C. Li, Angew. Chem. Int. Ed., 2015, 54, 9111-9114.

[61] R. Chen, S. Pang, H. An, J. Zhu, S. Ye, Y. Gao, F. Fan, C. Li, Nat. Energy, 2018, 3, 655-663.

[62] S. Iqbal, Z. Pan, K. Zhou, Nanoscale, 2017, 9, 6638-6642.

[63] X. Zhang, Z. Meng, D. Rao, Y. Wang, Q. Shi, Y. Liu, H. Wu, K. Deng, H. Liu, R. Lu, Energy Environ. Sci., 2016, 9, 841-849.

[64] Y. Chen, Z. Qin, X. Wang, X. Guo, L. Guo, RSC Adv., 2015, 5, 18159-18166.

[65] X. Zong, H. Yan, G. Wu, G. Ma, F. Wen, L. Wang, C. Li, J. Am. Chem. Soc., 2008, 130, 7176-7177.

[66] Q. Simon, D. Barreca, A. Gasparotto, C. Maccato, T. Montini, V. Gombac, G. Van Tendeloo, J. Mater. Chem., 2012, 22, 11739-11747.

[67] X. Li, J. Yu, J. Low, Y. Fang, J. Xiao, X. Chen, J. Mater. Chem. A, 2015, $3,2485-2534$.

[68] X. Li, J. Wen, J. Low, Y. Fang, J. Yu, Sci. China Mater., 2014, 57, 70-100.

[69] J. Wen, X. Li, W. Liu, Y. Fang, J. Xie, Y. Xu, Chin. J. Catal., 2015, 36, 2049-2070.

[70] X. Li, R. Shen, S. Ma, X. Chen, J. Xie, Appl. Surf. Sci., 2018, 430, 53-107.

[71] X. Li, J. Xie, C. Jiang, J. Yu, P. Zhang, Front. Env. Sci. Eng., 2018, 12, 14. 
[72] H. Katsumata, Y. Tachi, T. Suzuki, S. Kaneco, RSC Adv., 2014, 4, 21405-21409.

[73] X. Wang, G.Liu, L. Wang, Z. G. Chen, G. Q. Lu, H. M. Cheng, Adv. Energy Mater., 2012, 2, 42-46.

[74] W. Li, C. Feng, S. Dai, J. Yue, F. Hua, H. Hou, Appl. Catal. B, 2015, 168-169, 465-471.

[75] Y. Peng, Z. Guo, J. Yang, D. Wang, W. Yuan, J. Mater. Chem. A, 2014, 2, 6296-6300.

[76] S. S. Lee, H. Bai, Z. Liu, D. D. Sun, Appl. Catal. B, 2013, 140-141, 68-81.

[77] A. Thibert, F. A. Frame, E. Busby, M. A. Holmes, F. E. Osterloh, D. S. Larsen, J. Phys. Chem. Lett., 2011, 2, 2688-2694.

[78] Y. Hou, A. B. Laursen, J. Zhang, G. Zhang, Y. Zhu, X. Wang, I. Chorkendorff, Angew. Chem. Int. Ed., 2013, 52, 3621-3625.

[79] Y. P. Xie, Z. B. Yu, G. Liu, X. L. Ma, H. M. Cheng, Energy Environ. Sci., 2014, 7, 1895-1901.

[80] J. Zhang, M. Zhang, R. Q. Sun, X. Wang, Angew. Chem. Int. Ed., 2012, 124, 10292-10296.

[81] Y. Sui, J. Liu, Y. Zhang, X. Tian, W. Chen, Nanoscale, 2013, 5, 9150-9155.

[82] X. Xu, G. Liu, C. Randorn, J. T. Irvine, Int. J. Hydrogen Energy, 2011, 36, 13501-13507.

[83] J. Zhang, Y. Wang, J. Jin, J. Zhang, Z. Lin, F. Huang, J. Yu, ACS Appl. Mater. Interfaces, 2013, 5, 10317-10324.

[84] S. I. In, D. D. Vaughn II, R. E. Schaak, Angew. Chem. Int. Ed., 2012, 51, 3915-3918.

[85] F. Shen, W. Que, Y. Liao, X. Yin, Ind. Eng. Chem. Res., 2011, 50, 9131-9137.

[86] Y. He, L. Zhang, B. Teng, M. Fan, Environ. Sci. Technol., 2015, 49, 649-656.

[87] P. Li, Y. Zhou, H. Li, Q. Xu, X. Meng, X. Wang, Z. Zou, Chem. Commun., 2015, 51, 800-803.

[88] K. Sekizawa, K. Maeda, K. Domen, K. Koike, O. Ishitani, J. Am. Chem. Soc., 2013, 135, 4596-4599.

[89] X. Li, J. Chen, H. Li, J. Li, Y. Xu, Y. Liu, J. Zhou, J. Nat. Gas Chem., 2011, 20, 413-417.

[90] Y. He, Y. Wang, L. Zhang, B. Teng, M. Fan, Appl. Catal. B, 2014, 158-159, 20-29.

[91] J. Wang, G. Ji, Y. Liu, M. A. Gondal, X. Chang, Catal. Commun., 2014, 46, 17-21.

[92] S. Yang, D. Xu, B. Chen, B. Luo, X. Yan, L. Xiao, W. Shi, Appl. Surf. Sci., 2016, 383, 214-221.

[93] M. Bagheri, A. R. Mahjoub, B. Mehri, RSC $A d v ., 2014,4$, 21757-21764.

[94] J. Jiang, X. Zhang, P. Sun, L. Zhang, J. Phys. Chem. C, 2011, 115, 20555-20564.

[95] D. Xu, B. Cheng, S. Cao, J. Yu, Appl. Catal. B, 2015, 164, 380-388.

[96] J. Yu, S. Wang, J. Low, W. Xiao, Phys. Chem. Chem. Phys., 2013, 15, 16883-16890.

[97] M. Sun, G. Chen, Y. Zhang, Q. Wei, Z. Ma, B. Du, Ind. Eng. Chem. Res., 2012, 51, 2897-2903.

[98] S. J. A. Moniz, J. Tang, ChemCatChem, 2015, 7, 1659-1667.

[99] C. Ng, A. Iwase, Y. H. Ng, R. Amal, J. Phys. Chem. Lett., 2012, 3, 913-918.

[100] T. Wang, H. Meng, X. Yu, Y. Liu, H. Chen, Y. Zhu, Y. Zhang, RSC Adv., 2015, 5, 15469-15478.

[101] K. H. Reddy, S. Martha, K. M. Parida, Inorg. Chem., 2013, 52, 6390-6401.

[102] J. Li, W. Fang, C. Yu, W. Zhou, Y. Xie, Appl. Surf. Sci., 2015, 358, 46-56.

[103] J. S. Jang, S. M. Ji, S. W. Bae, H. C. Son, J. S. Lee, J. Photochem. Photobiol. A, 2007, 188, 112-119.
[104] Y. Chen, L. Wang, G. M. Lu, X. Yao, L. Guo, J. Mater. Chem., 2011, 21, 5134-5141.

[105] H. G. Yang, C. H. Sun, S. Z. Qiao, J. Zou, G. Liu, S. C. Smith, G. Q. Lu, Nature, 2008, 453, 638-641.

[106] G. Liu, C. Y. Jimmy, G. Q. M. Lu, H. M. Cheng, Chem. Commun., 2011, 47, 6763-6783.

[107] C. G. Read, E. M. Steinmiller, K. S. Choi, J. Am. Chem. Soc., 2009, 131, 12040-12041.

[108] T. Tachikawa, S. Yamashita, T. Majima, J. Am. Chem. Soc., 2011, 133, 7197-7204.

[109] X. Wang, Q. Xu, M. Li, S. Shen, X. Wang, Y. Wang, Z. Feng, J. Shi, H. X. Han, C. Li, Angew. Chem. Int. Ed., 2012, 51, 13089-13092.

[110] Q. Xie, H. T. Yu, Prog. Chem., 2009, 21, 406-418.

[111] G. L. Chiarello, E. Selli, L. Forni, Appl. Catal. B, 2008, 84, 332-339.

[112] J. Yang, D. Wang, H. Han, C. Li, Acc. Chem. Res., 2013, 46, 1900-1909.

[113] M. Abdennouri, R. Elmoubarki, A. Elmhammedi, A. Galadi, M. Baâlala, M. Bensitel, A. Boussaoud, Y. El hafiane, A. Smith, N. Barka, J. Mater. Environ. Sci., 2013, 4, 953-960.

[114] D. M. Tobaldi, R. C. Pullar, A. F. Gualtieri, A. Belen Jorge, R. Binions, P. F. McMillan, M. P. Seabra, J. A. Labrinch, CrystEngComm, 2015, 17, 1813-1825.

[115] P. Periyat, K. V. Baiju, P. Mukundan, P. K. Pillai, K. G. K. Warrier, Appl. Catal. A, 2008, 349, 13-19.

[116] A. Nilchi, S. Janitabar-Darzi, A. R. Mahjoub, S. Rasouli-Garmarodi, Colloids Surf. A, 2010, 361, 25-30.

[117] J. Ovenstone, K. Yanagisawa, Chem. Mater., 1999, 11, 2770-2774.

[118] I. S. Kwon, I. H. Kwak, H. G. Abbas, G. Jung, Y. Lee, J. Park, S. J. Yoo, J. G. Kim, H. S. Kang, Nanoscale, 2018, 10, 11349-11356.

[119] J. Liu, W. Qin, S. Zuo, Y. Yu, Z. Hao, J. Hazard. Mater., 2009, 163, 273-278.

[120] X. Li, Y. Xi, C. Hu, X. Wang, Mater. Res. Bull., 2013, 48, 295-299.

[121] X. Lü, W. Yang, Z. Quan, T. Lin, L. Bai, L. Wang, F. Huang, Y. Zhao, J. Am. Chem. Soc., 2014, 136, 419-426.

[122] Y. Huang, Z. Hu, K. Li, X. Shao, Comp. Mater. Sci., 2018, 143, 403-410.

[123] C. L. Yu, G. Li, S. Kumar, K. Yang, R. C. Jin, Adv. Mater., 2014, 26, 892-898.

[124] C. Yu, W. Zhou, L. Zhu, G. Li, K. Yang, R. Jin, Appl. Catal. B, 2016, 184, 1-11.

[125] M. Hamadanian, A. Reisi-Vanani, A. Majedi, Appl. Surf. Sci., 2010, 256, 1837-1844.

[126] Y. Bian, Y. Ma, Y. Shang, P. Tan, J. Pan, Appl. Surf. Sci., 2018, 430, 613-624.

[127] W. K. Wang, J. J. Chen, X. Zhang, Y. X. Huang, W. W. Li, H. Q. Yu, Sci. Rep., 2016, 6, 20491/1-20491/10.

[128] X. Zhang, J. Yao, M. Ali, J. Wei, H. Wang, L. Y. Yeo, J. R. Friend, D. R. MacFarlane, J. Mater. Chem. A, 2014, 2, 18791-18795.

[129] H. J. Jung, Y. L. Kim, H. Jang, M. Y. Choi, M. H. Kim, Mater. Lett., 2016, 181, 59-62.

[130] J. H. Jho, D. H. Kim, S. J. Kim, K. S. Lee, J. Alloys Compd., 2008, 459, 386-389.

[131] C. Li, G. Pang, S. Sun, S. Feng, J. Nano Part. Res., 2010, 12, 3069-3075.

[132] S. Sreekantan, R. Hazan, Z. Lockman, Thin solid films, 2009, 518, 16-21.

[133] R. Su, M. Christensen, Y. Shen, J. Kibsgaard, B. Elgh, R. T. Vang, R. Bechstein, S. Wendt, A. Palmqvist, B. B. Iversen, F. Besenbacher, J. Phys. Chem. C, 2013, 117, 27039-27046.

[134] L. Zhang, M. Jaroniec, Appl. Surf. Sci., 2018, 430, 2-17.

[135] Ì. Yílgör, K. Ahmad, W. P. Steckle Jr, D. Tyagi, G. L.Wilkes, J. E. McGrath, Polymer, 1984, 25, 1800-1806. 
[136] Y. Ma, Q. Xu, X. Zong, D. Wang, G. Wu, X. Wang, C. Li, Energy Environ. Sci., 2012, 5, 6345-6351.

[137] Y. Ma, Q. Xu, R. Chong, C. Li, J. Mater. Res., 2013, 28, 394-399.

[138] L. G. Devi, S. G. Kumar, B. N. Murthy, N. Kottam, Catal. Commun., 2009, 10, 794-798.

[139] H. Tian, J. Ma, K. Li, J. Li, Ceram. Int., 2009, 35, 1289-1292.

[140] A. Pichavant, E. Provost, M. H. Berger, W. Fürst, J. F. Hochepied, Colloids Surf. A, 2014, 462, 64-68.

[141] J. Su, C. Liu, D. Liu, M. Li, J. Zhou, ChemCatChem, 2016, 8, 3279-3286.

[142] Y. S. Jung, D. W. Kim, Y. S. Kim, E. K. Park, S. H. Baeck, J. Phys. Chem. Solids, 2008, 69, 1464-1467.

[143] M. Yuan, J. Zhang, S. Yan, G. Luo, Q. Xu, X. Wang, C. Li, J. Alloys Compd., 2011, 509, 6227-6235.

[144] Z. Zhang, G. Bo, C. Li, Z. H. Li, L. Cao, W. Liu, B. Dong, R. Gao, G. Su, Mater. Rev., 2016, 30, 10-15.

[145] M. Fujishima, H. Takatori, H. Tada, J. Colloid Interf. Sci., 2011, 361, 628-631.

[146] Ullah S, Ferreira-Neto E P, Pasa A A, S. Ullah, E. P. Ferreira-Neto, A. A. Pasa, C. C. J. Alcântara, J. J. S. Acuña, S. A. Bilmes, M. L. Martínez Ricci, R. Landers, T. Z. Fermino, U. P. Rodrigues-Filho, Appl. Catal. B, 2015, 179, 333-343.

[147] K. K. Bera, R. Majumdar, M. Chakraborty, S. K. Bhattacharya, J. Hazard. Mater., 2018, 352, 182-191.

[148] C. Wu, Q. Fang, Q. Liu, D. Liu, C. Wang, T. Xiang, A. Khalil, S. Chen, L. Song, Inorg. Chem. Front., 2017, 4, 663-667.

[149] H. Li, X. Shen, Y. Liu, L. Wang, J. Lei, J. Zhang, J. Alloys Compd., 2015, 646, 380-386.

[150] A. Testino, I. R. Bellobono, V. Buscaglia, C. Canevali, M. D'Arienzo, S. Polizzi, R. Scotti, F. Morazzoni, J. Am. Chem. Soc., 2007, 129, 3564-3575.

[151] Q. Wang, Z. Qiao, P. Jiang, J. Kuang, W. Liu, W. Cao, Solid State Sci., 2018, 77, 14-19.

[152] J. Li, H.Yang, Q. Li, D. Xu, CrystEngComm, 2012, 14, 3019-3026.

[153] M. Sun, S. Li, T. Yan, P. Ji, X. Zhao, K.Yuan, D. Wei, B, Du, J. Hazard. Mater., 2017, 333, 169-178.

[154] H. Wang, J. Li, P. Huo, Y. Yan, Q. Guan, Appl. Surf. Sci., 2016, 366, 1-8.

[155] D. Zeng, K. Yang, C. Yu, F. Chen, X. Li, Z. Wu, H. Liu, Appl. Catal. B, 2018, 237, 449-463.

[156] C. Yu, C. Fan, J. C. Yu, W. Zhou, K. Yang, Mater. Res. Bull., 2011, 46, 140-146.

[157] C. Yu, W. Zhou, J. Yu, F. Cao, X. Li, Chin. J. Chem., 2012, 30, 721-726.

[158] Z. Wu, D. Zeng, X. Liu, C. Yu, K. Yang, M. Liu, Res. Chem. Intermed., 2018, 44, 5595-6010.

[159] Y. Peng, K. K. Wang, T. Liu, J. Xu, B. G. Xu, Appl. Catal. B, 2017, 203, 946-954.

[160] G. Cai, L. Xu, B. Wei, J. Che, H. Gao, W. Sun, Mater. Lett., 2014, 120, 1-4.

[161] H. Lu, Q. Hao, T. Chen, L. Zhang, D. Chen, C. Ma, W. Yao, Y. Zhu, Appl. Catal. B, 2018, 237, 59-67.

[162] Y. Huang, W. Wang, Q. Zhang, J. J. Cao, R. J. Huang, W. Ho, S. C. Lee, Sci. Rep., 2016, 6, 23435/1-23435/9.

[163] R. Hu, X. Xiao, S. Tu, X. Zuo, J. Nan, Appl. Catal. B, 2017, 203, 879-888.

[164] H. Huang, K. Xiao, T. Zhang, F. Dong, Y. Zhang, Appl. Catal. B, 2017, 203, 879-888.

[165] J. Hou, C. Yang, Z. Wang, W. Zhou, S. Jiao, H, Zhu, Appl. Catal. B, 2013, 142-143, 504-511.

[166] W. Zeng, Y. Bian, S. Cao, Y. Ma, Y. Liu, A. Zhu, P. Tan, J Pan, ACS Appl. Mater. Interfaces, 2018, 10, 21328-21334.
[167] C. L. Yu, J. C. Yu, Catal. Lett., 2009, 129, 462-470.

[168] C. L. Yu, J. C. Yu, Catal. Lett., 2010, 140, 172-183.

[169] X. Zhu, S. Han, W. Feng, Q. Kong, Z. Dong, C. Wang, J. Lei, Q. Yi, RSC $A d v ., 2018,8,14249-14257$.

[170] Q. Wang, T. Hisatomi, Q. Jia, H. Tokudome, M. Zhong, C. Wang, Z. Pan, T. Takata, M. Nakabayashi, N. Shibata, Y. Li, I. D. Sharp, A. Kudo, T. Yamada, K. Domen, Nat. Mater., 2016, 15, 611-615.

[171] J. Zhang, Q. Xu, Z. Feng, M. Li, C. Li, Angew. Chem. Int. Ed., 2008, 47, 1766-1769.

[172] J.Yu, J. Low, W. Xiao, P. Zhou, M. Jaroniec, J. Am. Chem. Soc., 2014, 136, 8839-8842.

[173] R. G. Li, F. X. Zhang, D. Wang, J. Yang, M. R. Li, J. Zhu, X. Zhou, H. X. Han, C. Li, Nat. Commun., 2013, 4, 1432/1-1432/7.

[174] Y. Liu, Z. Wang, W. Wang, W. Huang, Chin. J. Catal., 2014, 310, 16-23.

[175] R. Chen, F. Fan, T. Dittrich, C. Li, Chem. Soc. Rev., 2018, 47, 8238-8262.

[176] J. Wang, J. Zhao, F. E. Osterloh, Energy Environ. Sci., 2015, 8, 2970-2976.

[177] M. Xie, X. Fu, L. Jing, P. Luan, Y. Feng, H. Fu, Adv. Energy Mater., 2014, 4, 1300995/1-1300995/6.

[178] R. G. Li, H. X. Han, F. X. Zhang, D. Wang, C. Li, Energy Environ. Sci., 2014, 7, 1369-1376.

[179] H. C. Liang, X. Z. Li, J. Hazard. Mater., 2009, 162, 1415-1422.

[180] C. Lv, G. Chen, J. Sun, Y. Zhou, Inorg. Chem., 2016, 55, 4782-4789.

[181] P. Ranjan, S. Nakagawa, H. Suematsu, R. Sarathi, INAE Lett., 2018, $1-8$.

[182] P. Russo, R. Liang, R. X. He, Y. N. Zhou, Nanoscale, 2017, 9, 6167-6177.

[183] Y. Jia, S. Shen, D. Wang, X. Wang, J. Shi, F. Zhang, H. X. Han, C. Li, J. Mater. Chem. A, 2013, 1, 7905-7912.

[184] K. Li, M. Han, R. Chen, S. L. Li, S. L. Xie, C. Mao, X. H. Bu, X. L. Cao, L. Z. Dong, P. Y. Feng, Y. Q. Lan, Adv. Mater., 2016, 28, 8906-8911.

[185] Y. X. Liu, Z. L. Wang, W. X. Huang, Appl. Surf. Sci., 2016, 389, 760-767.

[186] P. Devaraji, W. K. Jo, ChemCatChem, 2018, 10, 3813-3823.

[187] F. Xu, W. Xiao, B. Cheng, J. Yu, Int. J. Hydrogen. Energy, 2014, 39, 15394-15402.

[188] J. Y. Hu, S. S. Zhang, Y. H. Cao, H. J. Wang, H. Yu, F. Peng, ACS Sustain. Chem. Eng., 2018, 6, 10823-10832.

[189] Y. Qiu, F. Ouyang, Appl. Surf. Sci., 2017, 403, 691-698.

[190] R. Hinogami, Y. Nakamura, S. Yae, Y. Nakato, J. Phys. Chem. B, 1998, 102, 974-980.

[191] S. Wang, B. Y. Guan, Y. Lu, X. W. Lou, J. Am. Chem. Soc., 2017, 139, 17305-17308.

[192] S. Wang, B. Y. Guan, X. W. Lou, J. Am. Chem. Soc., 2018, 140, 5037-5040.

[193] H. Yao, H. Li, T. Hu, W. Hou, ChemCatChem, 2018, 10, 3726-3735.

[194] L. Hao, H. W. Huang, Y. X. Guo, X. Du, Y. H. Zhang, Appl. Surf. Sci., 2017, 420, 303-312.

[195] K. K. Kondamareddy, D. Neena, D. Z. Lu, T. Peng, M. A. M. Lopez, C. L. Wang, Z. H. Yu, N. Cheng, D. J. Fu, X. Z. Zhao, Appl. Surf. Sci., 2018, 456, 676-693.

[196] H. L. Gao, J. M. Liu, J. Zhang, Z. Q. Zhu, G. L. Zhang, Q. J. Liu, Chin. J. Catal., 2017, 38, 1688-1696.

[197] P. Makal, D. Das, Appl. Surf. Sci., 2018, 455, 1106-1115.

[198] W. K. Jo, S. Kumar, P. Yadav, S. Tonda, Appl. Surf. Sci., 2018, 445, 555-562.

[199] X. Zhao, Y. Su, X. Qi, X. Han, ACS Sustain. Chem. Eng., 2017, 5, 6148-6158.

[200] Y. L. Wang, W. Zhang, Z. H. Wang, Y. M. Cao, J. M. Feng, Z. L. Wang, 
Y. Ma, Chin. J. Catal., 2018, 39, 1500-1510.

[201] E. M. Samsudin, S. B. A. Hamid, J. C. Juan, W. J. Basirun, A. E. Kandjani, Appl. Surf. Sci., 2015, 359, 883-896.

[202] X. L. Wang, S. Shen, Z. C. Feng, C. Li, Chin. J. Catal., 2016, 37, 2059-2068.

[203] P. Moro, S. Stampachiacchiere, M. P. Donzello, G. Fierro, G.
Moretti, Appl. Surf. Sci., 2015, 359, 293-305.

[204] F. Dong, Z. Zhao, T. Xiong, Z. Ni, W. Zhang, Y. Sun, W. K. Ho, ACS Appl. Mater. Interfaces, 2013, 5, 11392-11401.

[205] Z. Liu, G. Wang, H. S. Chen, P. Yang, Chem. Commun., 2018, 54, $4720-4723$.

\title{
异质/同质相结高效光催化的研究进展：以相变构建为例
}

\author{
杨 凯 ${ }^{\mathrm{a}, \mathrm{d}}$, 李笑笑 ${ }^{\mathrm{a}}$, 余长林 ${ }^{\mathrm{a}, \mathrm{b},{ }^{*}}$, , 曾德涁 $^{\mathrm{a}}$, 陈范云 ${ }^{\mathrm{a}}$, 张开莲 ${ }^{\mathrm{a}}$, 黄微雅 ${ }^{\mathrm{a}}$, 纪红兵 ${ }^{\mathrm{c}, * *}$ \\ ${ }^{a}$ 江西理工大学冶金与化学工程学院, 江西贑州 341000 \\ b广东石油化工学院环境科学工程学院, 广东省石油化工污染过程与控制重点实验室, 广东茂名525000 \\ c 广东石油化工学院化学工程学院, 广东茂名 525000
}

\begin{abstract}
摘要: 半导体光催化剂在环境处理和能量转换方面有着巨大的应用潜力, 但由于电子-空穴对的复合作用, 半导体光催化剂 的光催化性能较低. 相结的存在是提高电子-空穴分离效率及光催化活性的有效途径, 对相结设计的深入研究是提高电荷 转移性能和效率的有效手段. 因此, 相结光催化技术的发展, 对于设计一个良好的相结和了解电子-空穴分离机理具有重要 的意义.

通常, 相结的构建需要特殊的制备技术以及良好的晶格匹配. 纳米异质结材料结合快速转移载流子的特点, 具有小尺 寸效应和颗粒限域效应的优点, 且具有单组分纳米材料或体相异质结不具有的独特特性. 纳米晶异质结可以促进光生电 子的快速转移, 根据两种半导体带的相对位置, 异质结可分为I型、II型和III型, 根据不同的电子转移途径可分为p-n型和Z型. 当 $\mathrm{p}$ 型半导体(空穴为多数电荷载流子)或 $\mathrm{n}$ 型半导体(电子为多数电荷载流子)密切接触时, 由于能带和其它性质的差异, 会形成结, 并在结的两侧形成空间电位差. 空间电位差的存在可以使产生光生载流子从一个半导体能级注入到另一个半 导体能级, 从而促进电子和空穴的分离, 提高光催化效率. 以 $\mathrm{p}-\mathrm{n}$ 结为例, 当它们在这两个区域共存时, 它们的边界层形成一 个薄的p-n结. 由于p 型区空穴浓度高, n型区电子浓度高, 结处存在电子和空穴的扩散现象. 在p-n结边界附近形成空间电荷 区, 从而在结内形成强的局域电场. 在结的局部电场作用下, 电荷在结两端累积形成电位差, 后者作为驱动力可以有效地 分离光生电荷.

近年来, 人们在纳米相结的设计和制备上做了大量工作以提高光催化剂活性. 虽然异质结具有优良的性能, 但异质结 的成分和元素并不是单一的, 它的形成也不是一步反应. 首先, 需要分别合成异质结的两个成分, 反应复杂, 耗时, 不环保. 与异质结相比, 同一材料通过相变构建的结也能实现光生载流子的高效分离. 同质化不需要引入其它要素, 因此引起了大 量关注. 在相变过程中, 大多数均由不同晶相的半导体形成, 如锐钠矿型/金红石型 $\mathrm{TiO}_{2}, \alpha-\beta$ 相 $\mathrm{Ga}_{2} \mathrm{O}_{3}$ 或六方/立方 CdS. 由于 化学成分相同, 半导体材料的能带结构不易改变. 因此, 对同晶材料的同质结研究较少. 虽然已有几篇关于异质相结的综 述论文, 但通过对外部诱导相变法制备相结的回顾, 仍可为读者提供有关该领域研究进展的新的认识. 本文对低成本、高 效率的相变思路在光催化领域中的应用进行了简要的总结, 并对其在光催化领域中的应用前景进行了展望.
\end{abstract}

关键词: 相变; 相结; 光催化; 有效电子转移

收稿日期: 2018-11-09. 接受日期: 2018-12-26. 出版日期: 2019-06-05.

*通讯联系人. 电话/传真: (0797)8312334; 电子信箱: yuchanglinjx@163.com; jihb@mail.sysu.edu.c

基金来源: 国家自然科学基金(21707055, 21567008, 21607064); 江西省5511科技创新人才(20165BCB18014); 江西省主要学术与 学科带头人(20172BCB22018); 江西省自然科学基金(20161BAB203090, 20181BAB213010, 20181BAB203018); 江西省教育厅青 年基金(GJJ160671); 福州大学国家重点实验室开放基金(SKLPEE-KF201712); 江西理工大学清江优秀人才项目; 江西理工大学 博士启动基金.

本文的电子版全文由Elsevier出版社在ScienceDirect上出版(http://www.sciencedirect.com/science/journal/18722067). 